Review

\title{
Pollution status of the Bohai Sea: An overview of the environmental quality assessment related trace metals
}

\author{
Xuelu Gao a,b,*, Fengxia Zhou ${ }^{\mathrm{a}, \mathrm{c}}$, Chen-Tung Arthur Chen ${ }^{\mathrm{b}}$ \\ a Key Laboratory of Coastal Environmental Processes and Ecological Remediation, Yantai Institute of Coastal Zone Research, Chinese Academy of Sciences, Yantai, Shandong 264003, China \\ b Department of Oceanography, National Sun Yat-Sen University, Kaohsiung 80424, Taiwan \\ c University of Chinese Academy of Sciences, Beijing 100049, China
}

\section{A R T I C L E I N F O}

\section{Article history:}

Received 26 June 2013

Accepted 30 September 2013

Available online 23 October 2013

\section{Keywords:}

Trace metals

Environmental status

Bohai Sea

China

\begin{abstract}
A B S T R A C T
It is well recognized that the ecosystem of the Bohai Sea is being rapidly degraded and the Sea has basically lost its function as a fishing ground. Billions of funds have been spent in slowing down, halting and finally reversing the environmental deterioration of the Bohai Sea. Although trace metals are routinely monitored, the data with high temporal resolution for a clear understanding of biogeochemical processes in the ecosystem of the Bohai Sea are insufficient, especially in the western literature. In this review, status of trace metal contamination in the Bohai Sea is assessed based on a comprehensive review of their concentrations recorded in the waters, sediments and organisms over the past decades. Studies show that metal contamination in the Bohai Sea is closely associated with the fast economic growth in the past decades. Concentrations of trace metals are high in coastal areas especially in the estuaries. Alarmingly high metal concentrations are observed in the waters, sediments and organisms from the western Bohai Bay and the northern Liaodong Bay, especially the coasts near Huludao in the northernmost area of the Bohai Sea, which is being polluted by industrial sewage from the surrounding areas. The knowledge of the speciation and fractionation of trace metals and the influence of submarine groundwater discharge on the biogeochemistry of trace metals in the Bohai Sea is far from enough and related work needs to be done urgently to get a better understanding of the influence of trace metals on the ecosystem of the Bohai Sea. A clear understanding of the trace metal pollution status of the Bohai Sea could not be achieved presently for lack of systematic cooperation in different research fields. It is quite necessary to apply the environmental and ecological modeling to the investigation of trace metals in the Bohai Sea and then provide foundations for the protection of the environment and ecosystem of the Bohai Sea.
\end{abstract}

(c) 2013 Elsevier Ltd. All rights reserved.

\section{Contents}

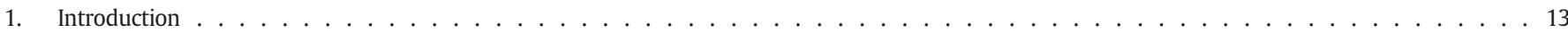

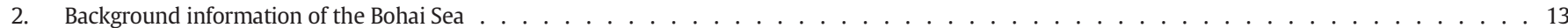

3. Current understanding of trace metals in the Bohai Sea . . . . . . . . . . . . . . . . . . . . . . . . . . . . . 15

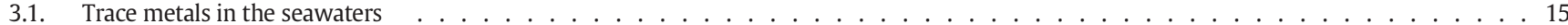

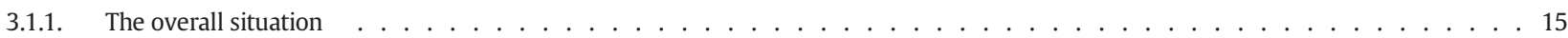

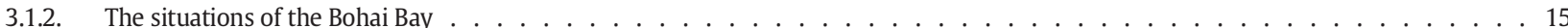

3.1.3. The situation of the liaodong Bay $\quad \ldots \ldots \ldots \ldots$

3.1.4. The situation of the Yellow River Estuary and its surrounding marine areas . . . . . . . . . . . . . . . . . . . . . . . 19

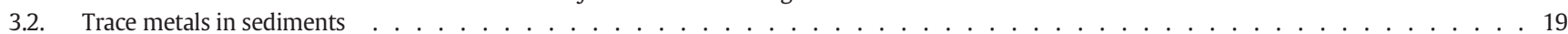

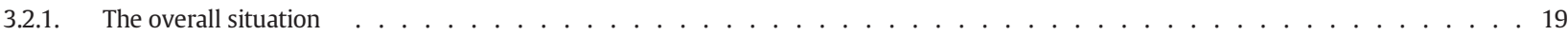

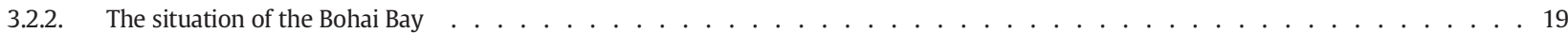

3.2.3. The situation of the Liaodong Bay _ . . . . . . . . . . . . . . . . . . . . . . . . . . . . . . . . . . . 22

3.2.4. Trace metals in sediments of the Laizhou Bay . . . . . . . . . . . . . . . . . . . . . . . . . . . 23

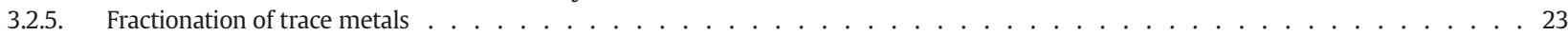

\footnotetext{
* Corresponding author at: Key Laboratory of Coastal Environmental Processes and Ecological Remediation, Yantai Institute of Coastal Zone Research, Chinese Academy of Sciences, Yantai, Shandong 264003, China. Tel.: + 86535 2109132; fax: + 865352109000.
} E-mail address: xlgao@yic.ac.cn (X. Gao). 


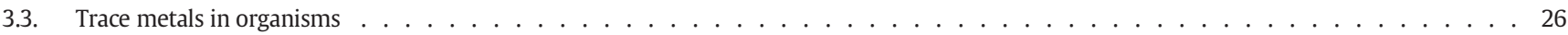

3.3.1. The situation of different metals . . . . . . . . . . . . . . . . . . . . . . . . . . . 26

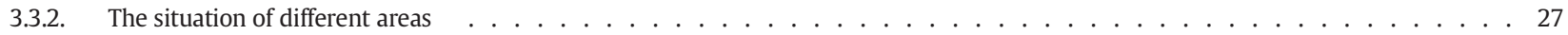

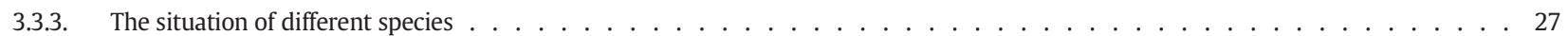

3.4. The relations between trace metals in the seawaters, sediments and organisms . . . . . . . . . . . . . . . . . . . . . . . 28

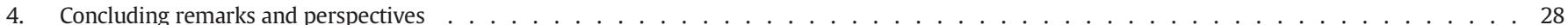

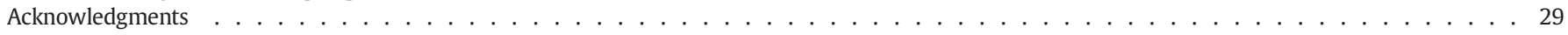

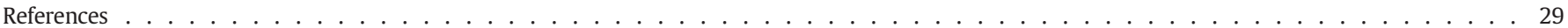

\section{Introduction}

Large quantities of different kinds of elements and compounds are discharged into coastal seas as contaminants each year by anthropogenic activities. The coastal seas act as filters trapping both natural and anthropogenic materials transferred from the continents to the open seas. Contaminants pose a serious threat to the coastal and marine ecosystems as well as to the inhabitants, resulting in changes in structures and functions of ecosystems, eutrophication, red-tide occurrence, increased mortality of fishes and benthos and decreased fishery yields, and great economic loss.

Metals are natural components of ecosystems and many of them are essential for the organisms. Only when their contents exceed certain values could they become contaminants to the environments. Excessive amount of trace elements is a serious environmental problem in many coastal ecosystems around the world. Many environmental quality guidelines, within which elements such as arsenic (As), cadmium $(\mathrm{Cd})$, chromium $(\mathrm{Cr})$, copper $(\mathrm{Cu})$, mercury $(\mathrm{Hg})$, nickel $(\mathrm{Ni})$, lead $(\mathrm{Pb})$ and zinc $(\mathrm{Zn})$ are usually used as criteria, have been developed to deal with environmental concerns as well as in response to regulatory programs (e.g., Burton, 2002).

The development of economy is always accompanied by environmental pollution, especially trace metal pollution (Pan and Wang, 2012). Since the initiation of the reform and opening-up policy in China at the end of the 1970s, the Bohai Sea has faced enormous anthropogenic stresses with the economic development in its coastal areas especially in the recent two decades. The coastal region surrounding the Bohai Sea is now one of the three most densely populated and industrialized zones in China (Fig. 1) and is called the Bohai Sea Economic Rim (BER). As a national base for manufacturing, heavy industry and chemicals, this region has gone through major changes in economy and infrastructures. The BER is rising as a northern economic powerhouse, rivaling the Pearl River Delta Economic Rim in the south and the Yangtze River Delta Economic Rim in the east. The BER is surrounded by Beijing and Tianjin, the second and the sixth largest megacity in China in terms of urban population, respectively, encompassing Hebei, Liaoning and Shandong provinces. The BER is about $5.2 \times 10^{5} \mathrm{~km}^{2}$ in area and 230 million in population, accounting for about $5.4 \%$ and $17.5 \%$ of China's total land area and population, respectively. In 2010, its gross domestic product was about 1.6 trillion US dollars, making up about 25\% of the country's total (National Bureau of Statistics of China, 2011).

While, the BER's high economic contribution rate obviously put the Bohai Sea under more environmental pollution pressure compared with other sea areas in China (Fig. 1). The Bohai Sea's semi-enclosed structure aggravates this situation. China Marine Environmental Quality Bulletin for the Year 2012 reported that the BER brought huge pressure of pollution and habitat destruction to the Bohai Sea; the ecosystem of estuaries and bays in the Bohai Sea were all in sub-healthy or unhealthy state (SOA, 2012). Many scholars have claimed that the Bohai Sea would turn into a dead sea sooner or later if no appropriate and effective measures were taken as quickly as possible.

The Chinese government did pay much attention to the Bohai Sea's environmental conditions. Based on thorough surveys, experts and officials have taken some measures. In 2001, China launched a 15-year program called 'Bohai Blue Sea Action Plan' to regulate and restore the ecosystem of the Bohai Sea with a budget of about 55.5 billion yuan, about 6.7 billion US dollars based on the exchange rate at that time. The goals of the program are that by 2005 the environmental pollution of the Bohai Sea could be controlled preliminarily and the trend of the ecological damage could get preliminary relief; by 2010 the Bohai Sea's environment could be preliminarily improved and the ecological damage could be controlled effectively; by 2015 the Bohai Sea's environment could improve markedly and its ecosystem could improve preliminarily. However, the program did not gain satisfying achievements as expected and it seems that nothing definite has been accomplished after more than 12 years since it was implemented. In 2008, another 40 billion yuan, about 5.8 billion US dollars was planned to be invested in remediating and conserving the Bohai Sea's ecology, conducting the environmental monitoring and surveillance, and building the warning and emergency systems during the 11th five-year plan of China. Besides, many other suggestions were proposed to save the ecosystem of the Bohai Sea, among which the most ambitious one was probably the one of improving the water circulation of the Bohai Sea by connecting it with the South Yellow Sea through an interbasin canal (Fig. 1; Wang, 2007).

A lot of literature has been published elaborating the situations of one to several trace metals related to environmental quality assessment of the Bohai Sea, most of which only focused on trace metals in the waters, sediments or organisms of the local/regional Bohai Sea. A comprehensive literature synthesis is necessary to have a clear understanding of the pollution situations of all the eight environmental quality assessment related trace metals - $\mathrm{As}, \mathrm{Cd}, \mathrm{Cr}, \mathrm{Cu}, \mathrm{Hg}, \mathrm{Ni}, \mathrm{Pb}$, and $\mathrm{Zn}$ - in the waters, sediments and organisms of the Bohai Sea and thus provide reference for policy and program making. To find out the deficiencies of the present research on these metals in the Bohai Sea is also an objective of this review.

\section{Background information of the Bohai Sea}

The Bohai Sea, also called Bohai or Bo Hai, is a semi-enclosed marginal sea of the northwestern Pacific Ocean on the northern coast of China. It is connected to the Yellow Sea on its east through the Bohai Strait (Fig. 1). The line connecting the southernmost end of the Liaodong Peninsula and the northernmost end of the Shandong Peninsula is geographically defined as the boundary between the Bohai Sea and the Yellow Sea. The Bohai Sea is often divided into three major bays, namely the Liaodong Bay in the north, the Bohai Bay in the west and the Laizhou Bay in the south, and the remaining area is called the Central Area (Fig. 1). It is approximately $7.7 \times 10^{4} \mathrm{~km}^{2}$ in area and $1.7 \times 10^{3} \mathrm{~km}^{3}$ in water volume. There are more than 40 rivers flowing into the Bohai Sea, among which the Yellow River, Haihe River, Luanhe River, Shuangtaizihe River and Liaohe River are the five major ones (Fig. 1). The mean depth of the Bohai Sea is $<20 \mathrm{~m}$, with the deepest region of about $70 \mathrm{~m}$ located near the northern coast of the Bohai Strait. In the Bohai Sea, the motion of water masses is dominated by semidiurnal and diurnal tides, which account for about $60 \%$ of the current variation and kinetic energy there (Chen et al., 2003).

The fundamental knowledge of the temporal and spatial variability of physical, chemical and biological components in the Bohai Sea is mainly gained from four comprehensive investigations across the 


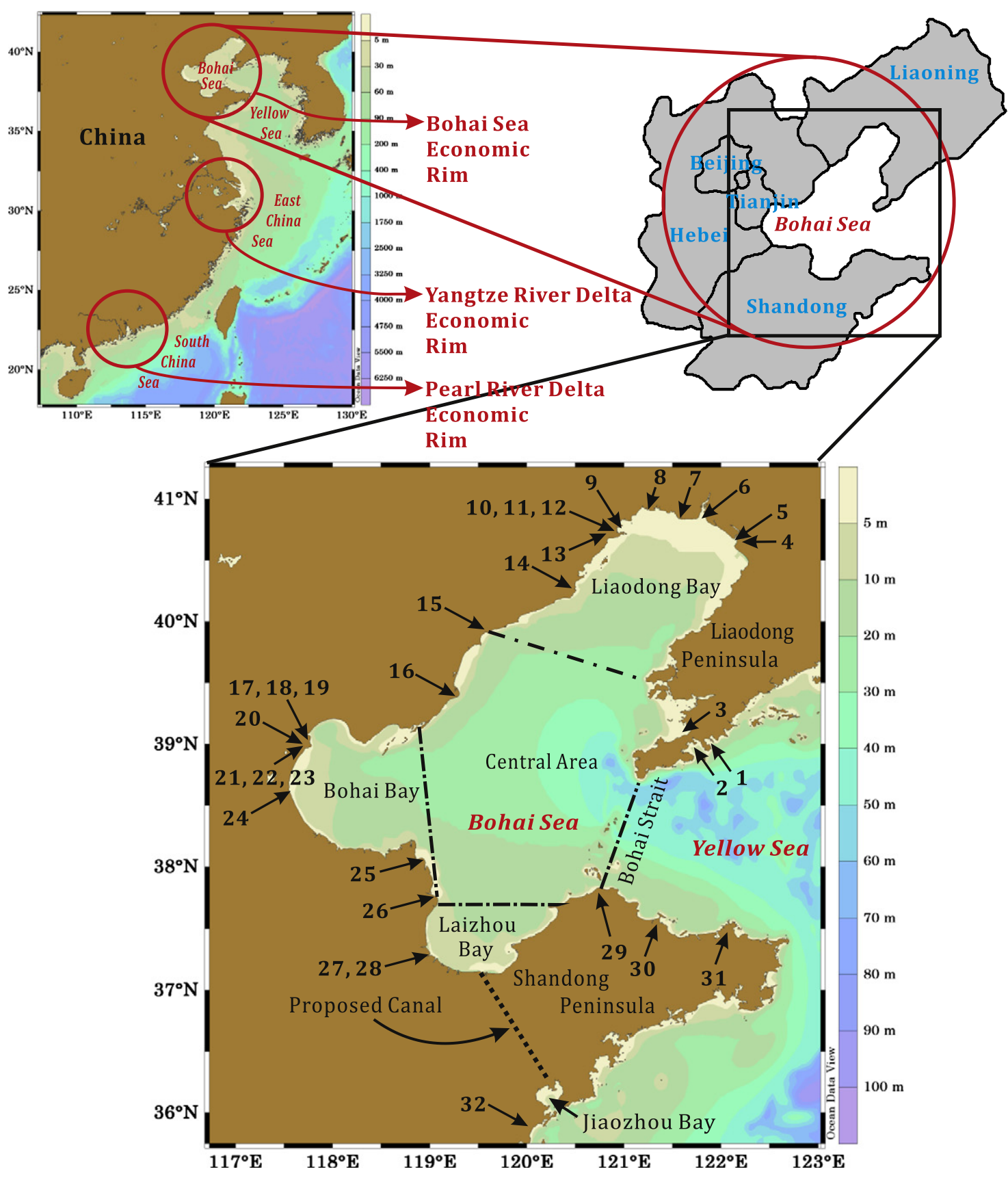

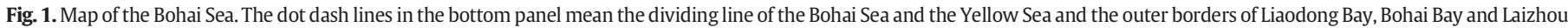

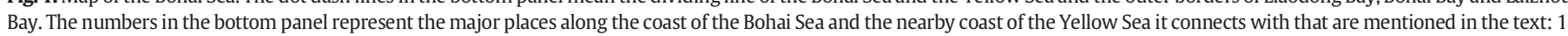

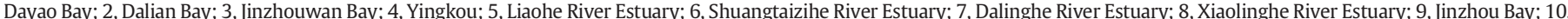

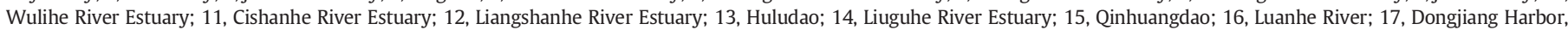

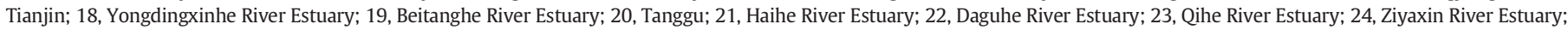
25, Dongying Harbor; 26, Yellow River Estuary; 27, Yangkou; 28, Xiaoqinghe River Estuary; 29, Penglai; 30, Yantai; 31, Weihai; and 32, Jiaonan.

whole area carried out monthly in 1959/1960 and 1982/1983, and seasonally in 1984/1985 and 1992/1993 (Wei et al., 2004). Two atlases and one volume of research collection have been published based on the latter three investigations (Editorial Board for Marine Atlas, 1991; Tang and Meng, 1997; Yellow Sea Fisheries Research Institute, 1991). Many important characteristics of phytoplankton such as the species composition, spatial distribution of dominant species and seasonal variation in biomass and primary production have been recognized (Cui et al., 1992; Diao, 1986; Fei, 1991; Kang, 1991; Li and Zhu, 1992; Yu and $\mathrm{Li}, 1993)$. The environmental factors such as sunshine duration, solar radiation, transparency, water temperature, stratification and nutrient conditions and their influences on algal growth were discussed.
Anthropogenic pollution, especially some industrial effluents, has caused notable effects on the species diversity of the phytoplankton and benthos communities in the Bohai Sea (Liu et al., 2011b; Xu, 2011). The decrease of benthos community diversity caused by the environmental pollution could further cause the decline of fishery and influence the feeding habit of benthos. The combined pollution of $\mathrm{Cd}$, $\mathrm{Hg}, \mathrm{Pb}$ and petroleum hydrocarbons ( $\mathrm{PHs}$ ) has been found responsible for the notable reduction of the population growth rates of common fishery species in the Bohai Sea (Xu, 2011).

Fishery species in the Bohai Sea has been declining significantly in recent decades. The mean trophic level of fishing catch exhibited a decreasing trend during 1956/2000 (Xu, 2011). The mean trophic 
level declined from 4.06 in 1959/1960 to 3.41 in 1998/1999, i.e. about 0.2 decade $^{-1}$ in the Bohai Sea, higher than that of the global trend during the same period (Pauly et al., 1998; Zhang et al., 2007). Besides the fishing pressure and climate changes, the decrease of freshwater input, the decline of food organisms and reactive silicate supply, and the increase of the molar ratio of dissolved inorganic nitrogen (ammonia + nitrate + nitrite; DIN) to dissolved inorganic phosphorous (DIP) (N/P ratio) and $\mathrm{Pb}$ concentration were thought to be responsible for such decrease of trophic level directly or indirectly (Xu, 2011).

\section{Current understanding of trace metals in the Bohai Sea}

\subsection{Trace metals in the seawaters}

Trace metals in the seawaters of the Bohai Sea come from many sources, such as river discharge, atmospheric deposition, biodegradation, etc. Their concentration decrease can be caused by water dilution, adsorption and settlement and discharging into the Yellow Sea. According to current understanding, the trace metals in the seawaters of the Bohai Sea is mainly from river discharge, which brings high concentrations of trace metals, and other pathways influencing their concentrations have relatively little impact compared with river discharge.

\subsubsection{The overall situation}

Investigations of trace metals in dissolved pool covering the whole area of the Bohai Sea have not been reported much in public literature. Related works were mainly carried out in the Bohai Bay and the Liaodong Bay, especially in their nearshore areas. Related information is particularly scarce for the Laizhou Bay. Seasonal, monthly or other short-time-scale temporal variation characteristics of dissolved trace metals are not available. The dissolved $\mathrm{Cr}$ and $\mathrm{Ni}$ are reported to be much less compared with other environmental quality criteria related trace metals (Table 1). Based on the data in Table 1, the maximum concentrations of trace metals ever reported in the seawaters of the Bohai Sea are presented in Fig. 2a. It reveals that the coastal waters had the highest concentration of trace metals than other areas of the Bohai Sea. Among the three bays, the Bohai Bay seemed to be the most anthropogenically influenced considering the highest concentrations of $\mathrm{As}, \mathrm{Cr}, \mathrm{Pb}$ and $\mathrm{Zn}$ in the seawaters. The Liaodong Bay was next to the Bohai Bay and the maximum values of $\mathrm{Cd}$ and $\mathrm{Cu}$ were in the waters of the Jinzhou Bay and the northern Liaodong Bay, respectively. It is worth noting that the maximum concentrations of trace metals in Fig. 2 were not all recorded in the same period. The figure shows the integrated information about the extreme cases which ever occurred in the Bohai Sea in history.

The National Standard of China for Seawater Quality (SWQ) GB 3097-1997 (SEPA, 1997), classifying four levels corresponding to different function zones, has always been used as the evaluation criterion. SWQ Grade I is suitable for marine fishery, marine natural reserves and rare and endangered marine protected areas. Grade II applies to aquaculture, bathing beach, sea sports or recreation areas where people contact seawaters directly and industrial water areas that have direct relation with human consumption. Grade III is appropriate for common industrial water areas and coastal scenery tourist areas. Grade IV applies to sea port waters and the ocean development areas.

The spatial distribution of dissolved $\mathrm{As}, \mathrm{Cd}, \mathrm{Cu}, \mathrm{Hg}$ and $\mathrm{Pb}$ in both surface and bottom waters of all the main parts of the Bohai Sea was reported by Wang and Wang (2007) based on a study carried out in August 2003. It showed that the dissolved $\mathrm{Pb}$ was the only one among the five studied elements in the Bohai Sea with the average concentration slightly higher than SWQ Grade I, which indicated that this water area was not suitable for marine fishery, marine natural reserves and rare and endangered marine organisms' protection (Table 1; SEPA, 1997). The spatial distribution pattern of $\mathrm{Pb}$ in the surface water was similar to those of $\mathrm{As}, \mathrm{Cu}$ and $\mathrm{Cd}$, and their concentration isopleths generally indicated the decreasing values from the bays to the Central Area. Only dissolved $\mathrm{Hg}$ showed the characteristic that the high concentrations not only appeared in the Liaodong Bay, the Bohai Bay and the Laizhou Bay, but also in the Central Area (Wang and Wang, 2007). Based on the paired samples $t$-test, Wang and Wang (2007) found that the concentrations of dissolved As, Cd, Cu and $\mathrm{Pb}$ in the waters of the Bohai Sea showed no significant differences between surface and bottom layers, while the concentrations of dissolved $\mathrm{Hg}$ were significantly different in the two layers and its average concentration was higher in bottom than in surface water which was probably owing to the benthic flux.

The terrigenous input of pollutants was thought to be the main influencing factor for the detected distribution patterns of dissolved trace metals followed by the dynamics of seawaters, benthic flux from bottom sediment and biochemical processes (Wang and Wang, 2007). The report of Wang and Wang (2007) also showed that the average concentrations of studied dissolved trace metals presented a declining trend comparing with the earlier data.

From July 2006 to October 2007, the concentrations and spatial distribution characteristics of dissolved $\mathrm{As}, \mathrm{Cd}, \mathrm{Cr}, \mathrm{Cu}, \mathrm{Hg}, \mathrm{Pb}$ and $\mathrm{Zn}$ in surface waters were investigated in the area of $37.2^{\circ}-40.3^{\circ} \mathrm{N}$ and $118.0^{\circ}-121.7^{\circ} \mathrm{E}$, which covered most areas of the Bohai Sea excluding the westernmost area of the Bohai Bay and the northernmost area of the Liaodong Bay (Fig. 1; Pan et al., 2012). The average concentrations indicated that $\mathrm{As}, \mathrm{Cd}$ and $\mathrm{Hg}$ were the highest in summer, $\mathrm{Cu}$ was the highest in winter, $\mathrm{Cr}$ was the highest in spring and summer, and $\mathrm{Pb}$ and $\mathrm{Zn}$ were the highest in spring (Table 1 ). The nearshore areas around and between the Liuguhe River Estuary and Qinhuangdao (Fig. 1) had relatively high concentrations of $\mathrm{As}, \mathrm{Cd}, \mathrm{Cr}, \mathrm{Cu}, \mathrm{Hg}, \mathrm{Pb}$ and $\mathrm{Zn}$ in summer or autumn (Pan et al., 2012).

Environmental risk assessment of dissolved $\mathrm{Cd}, \mathrm{Cu}, \mathrm{Hg}$ and $\mathrm{Pb}$ showed that in the Bohai Sea seawaters the major risk agents were $\mathrm{Hg}$ and $\mathrm{Pb}$, and the localized risk agent was $\mathrm{Cu}$, while the risk from $\mathrm{Cd}$ was at an acceptable level (Wang et al., 2010a). The coastal waters near estuaries and big cities like Tianjin and Jinzhou had higher potential risks. The Bohai Bay where the trace metal pollution was most serious had the highest environmental risks of dissolved $\mathrm{Cu}, \mathrm{Hg}$ and $\mathrm{Pb}$ (Wang et al., 2010a).

\subsubsection{The situations of the Bohai Bay}

Due to the fact that the Bohai Bay is surrounded by highly industrialized areas and is semi-enclosed, the pollution status has aroused many concerns. Long-term monitoring data are available for dissolved trace metals in the seawaters of the Bohai Bay.

During 1996 to 2005, dissolved $\mathrm{Cd}, \mathrm{Cu}, \mathrm{Hg}, \mathrm{Pb}$ and $\mathrm{Zn}$ in the seawaters of the Bohai Bay were investigated. Their maximum concentrations recorded were $0.89,16.3,0.23,40.4$ and $422 \mu \mathrm{g} \mathrm{l}^{-1}$, respectively (Dai et al., 2009). The concentrations of $\mathrm{Cd}$ in all samples were below SWQ Grade I, while $\mathrm{Cu}, \mathrm{Hg}$, $\mathrm{Pb}$ and $\mathrm{Zn}$, with their percentage being $2.7 \%, 0.4 \%, 30.4 \%$ and $30.0 \%$ respectively, fell in the threshold value of SWQ Grade III, suggesting that the water in this area was appropriate for general industrial use and coastal scenery tour. Cd was not the main pollutant in the seawaters of the Bohai Bay according to the study of Dai et al. (2009), and this fact could further be proved by the reports of Peng et al. (2009) and Zhang et al. (2010c).

Mao et al. (2009) got a similar result as Dai et al. (2009) did showing that the seawaters in the Bohai Bay were mainly polluted by $\mathrm{Hg}, \mathrm{Pb}$ and $\mathrm{Zn}$, and only slightly polluted by $\mathrm{Cd}$ and $\mathrm{Cu}$ in the period of 1996 to 2005. Their results also indicated that the concentrations of $\mathrm{Cd}, \mathrm{Cu}, \mathrm{Hg}$, $\mathrm{Pb}$ and $\mathrm{Zn}$ did not show significant seasonal variations in the seawaters of the Bohai Bay, which was possibly influenced by the relatively stable surrounding environment in a year round, while their variation trends with time on a 10-year scale were different (Mao et al., 2009). The 10 -year monitoring showed that these five kinds of trace metals in the Bohai Sea water changed significantly (Mao et al., 2009). Concentrations 
Table 1

The summary of dissolved trace element concentrations ( $\mu \mathrm{g} \mathrm{l}^{-1}$ for all elements) in waters of the Bohai Sea and relevant guideline values of different criteria.

\begin{tabular}{|c|c|c|c|c|c|c|c|c|c|c|c|c|}
\hline Location & Sampling date & Sampling size & & As & $\mathrm{Cd}$ & $\mathrm{Cr}$ & $\mathrm{Cu}$ & $\mathrm{Hg}$ & $\mathrm{Ni}$ & $\mathrm{Pb}$ & $\mathrm{Zn}$ & References \\
\hline \multirow[t]{11}{*}{ Bohai Sea } & Aug., 2002 & 52 & Mean & na $^{\text {a }}$ & 0.49 & na & 3.35 & 0.07 & na & 3.29 & na & Wang et al. (2010a) \\
\hline & Aug., 2003 & 52 & Mean & na & 0.35 & na & 3.13 & 0.27 & na & 1.16 & na & Wang et al. (2010a) \\
\hline & Aug., 2003 & 42 & Mean \pm SD & $1.5 \pm 0.3$ & $0.31 \pm 0.12$ & na & $1.9 \pm 0.8$ & 0.03 & na & $1.1 \pm 0.4$ & na & $\begin{array}{l}\text { Wang and Wang } \\
\text { (2007) }\end{array}$ \\
\hline & $\begin{array}{l}\text { Jul. } 2006 \text { to } \\
\text { Oct. } 2007\end{array}$ & na & Range in spring & $1.2-1.6$ & $0.080-0.400$ & $1.8-5.3$ & $1.33-6.92$ & $0.016-0.089$ & na & $0.87-5.67$ & $14.8-35.4$ & Pan et al. (2012) \\
\hline & & na & Mean in spring & 1.3 & 0.160 & 3.5 & 3.22 & 0.047 & na & 2.79 & 18.4 & \\
\hline & & na & Range in summer & $1.0-3.4$ & $0.052-0.466$ & $1.9-5.4$ & $1.29-8.24$ & $0.029-0.140$ & na & $1.04-6.21$ & $11.1-34.9$ & \\
\hline & & na & Mean in summer & 1.6 & 0.168 & 3.5 & 3.38 & 0.064 & na & 2.27 & 17.5 & \\
\hline & & na & Range in autumn & $0.5-2.8$ & $0.080-0.220$ & $2.1-4.4$ & $1.73-4.47$ & $0.031-0.091$ & na & $0.88-3.41$ & $11.9-33.9$ & \\
\hline & & na & Mean in autumn & 1.0 & 0.150 & 3.2 & 2.99 & 0.046 & na & 1.89 & 17.7 & \\
\hline & & na & Range in winter & 0.7 & $0.057-0.226$ & $1.2-4.6$ & $1.23-6.77$ & $0.017-0.056$ & na & $1.08-6.30$ & $11.6-30.9$ & \\
\hline & & na & Mean in winter & 2.3 & 0.144 & 3.2 & 3.48 & 0.041 & na & 2.75 & 17.0 & \\
\hline \multirow[t]{4}{*}{ Bohai Bay } & $\begin{array}{l}\text { May, Aug. \& } \\
\text { Oct., 1996-2005 }\end{array}$ & 22 & Mean \pm SD & na & $0.20 \pm 0.13$ & na & $3.22 \pm 2.40$ & $0.05 \pm 0.03$ & na & $4.43 \pm 4.77$ & $43.92 \pm 44.56$ & Mao et al. (2009) \\
\hline & 2000 & 22 & Mean \pm SD & na & na & na & $5.69 \pm 3.98$ & $0.06 \pm 0.04$ & na & na & $73.01 \pm 61.30$ & Dai et al. (2009) \\
\hline & 2004 & 17 & Max & 3.44 & 0.79 & na & 16.3 & 0.22 & na & 27.17 & 387 & Peng et al. (2009) \\
\hline & & & Mean $\pm S D$ & $1.53 \pm 0.71$ & $0.38 \pm 0.19$ & na & $4.43 \pm 2.85$ & $0.08 \pm 0.05$ & na & $8.38 \pm 6.2$ & $79.65 \pm 85.06$ & \\
\hline \multirow[t]{8}{*}{ Bohai Bay } & June, 2003 & 20 & Ranges & $0.79-2.06$ & $0.08-0.19$ & $0.11-1.15$ & $1.60-4.10$ & $0.004-0.09$ & na & $3.63-12.65$ & $3.0-55.0$ & Meng et al. (2008) \\
\hline & & & Mea \pm SD & $1.26 \pm 0.41$ & $0.12 \pm 0.03$ & $0.40 \pm 0.26$ & $2.54 \pm 0.07$ & $0.04 \pm 0.02$ & na & $7.10 \pm 2.57$ & $26.9 \pm 14.2$ & \\
\hline & Apr., 2008 & 20 & Range & $1.03-1.26$ & na & na & na & na & na & na & na & Duan et al. (2010) \\
\hline & & & Mean & 1.18 & na & na & na & na & na & na & na & \\
\hline & Apr., 2008 & 20 & Range & na & na & na & $2.22-3.12$ & $0.035-0.068$ & na & $1.25-2.02$ & na & Zhang et al. (2010b) \\
\hline & & & Mean & na & na & na & 2.68 & 0.048 & na & 1.63 & na & \\
\hline & Apr., 2008 & 20 & Range & na & $0.107-0.182$ & na & na & na & na & na & $15.2-24.3$ & Zhang et al. (2010c) \\
\hline & & & Mean & na & 0.15 & na & na & na & na & na & 19.68 & \\
\hline Dongying Harbor & Jun., 2001 & 12 & Max & na & na & na & na & 2.59 & na & na & na & Liu et al. (2003) \\
\hline \multirow[t]{2}{*}{ Northern Liaodong Bay } & Jun. \& Aug., & 16 & Range & na & $0.016-3.48$ & na & $1.04-25.49$ & na & na & $n d^{b}-16.76$ & nd- 88.40 & Wan et al. (2008a) \\
\hline & $2001-2005$ & & Mean & na & 0.995 & na & 4.34 & na & na & 3.21 & 31.54 & \\
\hline Coastal watersheds along & Oct., 2008 & 29 & Range & na & na & na & na & $0.87-1.3$ & na & na & na & Luo et al. (2012) \\
\hline the N Bohai Sea & & & Mean & na & na & na & na & $1.0 \pm 0.11$ & na & na & na & \\
\hline
\end{tabular}




\begin{tabular}{|c|c|c|c|c|c|c|c|c|c|c|c|c|}
\hline $\begin{array}{l}\text { Upstream regions of } \\
\text { coastal watersheds } \\
\text { along the N Bohai Sea }\end{array}$ & Oct., 2008 & 17 & $\mathrm{GM} \pm \mathrm{SD}^{\mathrm{c}}$ & na & $0.20 \pm 0.031$ & na & na & na & na & na & $7.0 \pm 4.52$ & Luo et al. (2013) \\
\hline $\begin{array}{l}\text { Downstream regions of } \\
\text { coastal watersheds } \\
\text { along the N Bohai Sea }\end{array}$ & Oct., 2008 & 12 & $\mathrm{GM} \pm \mathrm{SD}$ & na & $0.37 \pm 0.018$ & na & na & na & na & na & $22 \pm 10$ & Luo et al. (2013) \\
\hline \multirow[t]{10}{*}{ Jinzhou Bay } & $1987-1990$ & na & Range & na & $0.6-5.0$ & na & $0.18-1.30$ & na & na & $1.36-3.14$ & $6.16-68.6$ & Ma et al. (1995) \\
\hline & & & Mean & na & 1.9 & na & 0.40 & na & na & 1.92 & 21.1 & \\
\hline & Aug., 2005 & 30 & Range & na & $0.79-3.09$ & na & $0.73-5.62$ & na & na & nd-1.67 & $4.31-53.33$ & Wan et al. (2008b) \\
\hline & & & Mean \pm SD & na & $1.65 \pm 0.69$ & na & $1.71 \pm 0.85$ & na & na & $0.38 \pm 0.52$ & $23.14 \pm 13.08$ & \\
\hline & Jun., 2006 & 25 & Range & na & $0.94-3.01$ & na & $0.76-13.2$ & na & na & $0.2-2.91$ & $10.39-101.95$ & Wan et al. (2008b) \\
\hline & & & Mean $\pm S D$ & na & $2.01 \pm 0.68$ & na & $3.49 \pm 2.84$ & na & na & $1.19 \pm 0.78$ & $39.16 \pm 28.71$ & \\
\hline & Aug., 2006 & 30 & Range & na & $1.33-3.08$ & na & $0.88-4.81$ & na & na & nd-6.05 & $3.18-65.3$ & Wan et al. (2008b) \\
\hline & & & Mean $\pm S D$ & na & $1.94 \pm 0.56$ & na & $2.28 \pm 1.06$ & na & na & $1.13 \pm 1.48$ & $21.77 \pm 13.83$ & \\
\hline & Sep., 2009 & 20 & Range & $1.14-3.65$ & $0.56-2.04$ & na & $1.26-2.49$ & $0.006-0.058$ & na & $0.21-1.39$ & $1.58-25.73$ & Wang et al. (2012) \\
\hline & & & Mean & 2.19 & 0.92 & na & 3.06 & 0.030 & na & 0.61 & 11.87 & \\
\hline \multirow{2}{*}{$\begin{array}{l}\text { Yellow River Estuary } \\
\text { and adjacent sea }\end{array}$} & May, 2009 & 30 & Range & $0.43-1.40$ & $0.10-3.22$ & na & $0.10-4.46$ & $0.004-0.028$ & na & $0.22-1.33$ & $12.00-81.84$ & Tang et al. (2010) \\
\hline & & & Mean & 0.92 & 0.68 & na & 2.65 & 0.013 & na & 0.51 & 37.67 & \\
\hline Jiaozhou Bay & 1992, 1993 & 22 & Mean & nd & 1.13 & na & 3.48 & 0.028 & na & 22.72 & 48.93 & $\begin{array}{l}\text { Cui et al. (1997) } \\
\text { Ling (2010) }\end{array}$ \\
\hline North Yellow Sea & 2007 & 38 & Mean & nd & 0.14 & na & 0.8 & nd & na & 0.35 & 3.8 & Tian et al. (2009) \\
\hline South Yellow Sea & 2003 & na & Mean & 2.33 & 0.078 & na & 1.41 & 0.0036 & na & 0.37 & 6.21 & He et al. (2008) \\
\hline South China Sea & 1998 & na & Mean & nd & 0.007 & na & 0.100 & nd & na & 0.058 & 0.086 & Yu (2003) \\
\hline $\begin{array}{l}\text { Changjiang Estuary and } \\
\text { Hangzhou Bay }\end{array}$ & 2006 & 71 & Mean & 3.6 & 0.387 & na & 1.99 & 0.172 & na & 0.9 & 6.1 & Sun et al. (2009) \\
\hline Grade I $^{\mathrm{d}}$ & & & & $\leq 20$ & $\leq 1.0$ & $\leq 50$ & $\leq 5.0$ & $\leq 0.05$ & $\leq 5.0$ & $\leq 1.0$ & $\leq 20$ & SEPA (1997) \\
\hline Grade II $^{\mathrm{e}}$ & & & & $\leq 30$ & $\leq 5$ & $\leq 100$ & $\leq 10$ & $\leq 0.2$ & $\leq 10$ & $\leq 5.0$ & $\leq 50$ & SEPA (1997) \\
\hline Grade III ${ }^{\mathrm{f}}$ & & & & $\leq 50$ & $\leq 10$ & $\leq 200$ & $\leq 50$ & $\leq 0.5$ & $\leq 20$ & $\leq 10$ & $\leq 100$ & SEPA (1997) \\
\hline
\end{tabular}

a na: not available.
b nd: not detected.

c $\mathrm{GM} \pm \mathrm{SD}$ : geometic mean \pm standard deviation.

d Grade I: National Standard of China for Seawater Quality GB 3097-1997 Grade I.

e Grade II: National Standard of China for Seawater Quality GB 3097-1997 Grade II.

${ }^{\mathrm{f}}$ Grade III: National Standard of China for Seawater Quality GB 3097-1997 Grade III. 
of $\mathrm{Cu}$ and $\mathrm{Zn}$ showed great disparity with annual variation. While, concentrations of $\mathrm{Cd}, \mathrm{Hg}$ and $\mathrm{Pb}$ showed relatively simple change and presented a significant increasing trend (Mao et al., 2009).

In the coastal waters of the Bohai Bay, among $\mathrm{Cu}, \mathrm{Pb}, \mathrm{Zn}, \mathrm{Cd}, \mathrm{Cr}, \mathrm{As}$ and $\mathrm{Hg}, \mathrm{Pb}$ and $\mathrm{Zn}$ were found as the main trace metal pollutants on a larger spatial scale in June 2003 (Meng et al., 2008). Before 2001, Pb in the coastal waters of the Bohai Bay originated primarily from river discharge; yet after 2001, its levels did not decrease with the declining of annual runoff, indicating that the $\mathrm{Pb}$ input by atmospheric deposition had increased due to the use of leaded petrol in motor cars during that period (Meng et al., 2008). Higher concentration of $\mathrm{Zn}$ in the Bohai Bay was the result of the terrestrial sewage discharge near the mouths of Beitang and Dagu estuaries (Meng et al., 2008).

Based on the most recent surveys reported in literature, in April 2008, among $\mathrm{As}, \mathrm{Cd}, \mathrm{Cu}, \mathrm{Hg}, \mathrm{Pb}$ and $\mathrm{Zn}$, only the average value of $\mathrm{Pb}$ in the seawaters of the Bohai Bay exceeded the range of SWQ Grade I (Duan et al., 2010; Zhang et al., 2010b, 2010c). So, as to the whole Bohai Bay, the pollution situation of trace metals $\mathrm{As}, \mathrm{Cd}, \mathrm{Cu}, \mathrm{Hg}$ and $\mathrm{Zn}$ in the seawaters may not be serious in recent years.

A rough historical change of trace metals in the Bohai Bay during 1996 and 2008 could be attained after comparing relevant data in Table 1. As, $\mathrm{Cd}, \mathrm{Cu}, \mathrm{Hg}, \mathrm{Pb}$ and $\mathrm{Zn}$ showed a decreasing trend. This may be the result of 'Bohai Blue Sea Action Plan' program's implementation.

Concentrations of $\mathrm{As}, \mathrm{Cd}, \mathrm{Cu}, \mathrm{Hg}, \mathrm{Pb}$ and $\mathrm{Zn}$ in the inner part of the Bohai Bay, especially in the estuaries, were higher than those in the outer part, manifesting river discharge sources (Dai et al., 2009; Liu et al., 2003; Mao et al., 2009; Meng et al., 2008; Peng et al., 2009; Zhang et al., 2010c). Moreover, concentrations of $\mathrm{Cd}, \mathrm{Hg}, \mathrm{Pb}$ and $\mathrm{Zn}$ decreased from the south to the north in the Bohai Bay and concentrations of $\mathrm{Cu}$ appeared to be contrary for their different sources from different river estuaries, different industrial wastewater outfalls, different mariculture areas, different sizes of ports and so on (Mao et al., 2009). Unlike other trace metals, $\mathrm{Hg}$ had relatively higher concentrations which occurred not only in inshore but also in offshore areas (Dai et al., 2009; Peng et al., 2009). On a whole, transportation of pollutants from land to sea was supposed to be the main factor influencing the distribution patterns of dissolved trace metals in the Bohai Bay (Duan et al., 2010; Peng et al., 2009).

\subsubsection{The situation of the Liaodong Bay}

As the largest bay of the Bohai Sea, the Liaodong Bay needs 15 years to complete a water exchange cycle (Wan et al., 2008a). Major rivers discharging into it are mainly the Liaohe River, Shuangtaizihe River, Dalinghe River, Xiaolinghe River, Wulihe River and Cishanhe River (Fig. 1). These rivers were thought to be the most important sources of trace metals to the bay (Wan et al., 2008a, 2008b).

It was reported that from 2001 to 2005 the average concentrations of dissolved metals in the northern Liaodong Bay were 0.995, 4.34, 3.21, and $31.54 \mu \mathrm{g} \mathrm{l}^{-1}$ for $\mathrm{Cd}, \mathrm{Cu}, \mathrm{Pb}$ and $\mathrm{Zn}$, respectively, with the concentrations of $\mathrm{Pb}$ and $\mathrm{Zn}$ being higher than SWQ Grade I (Table 1;
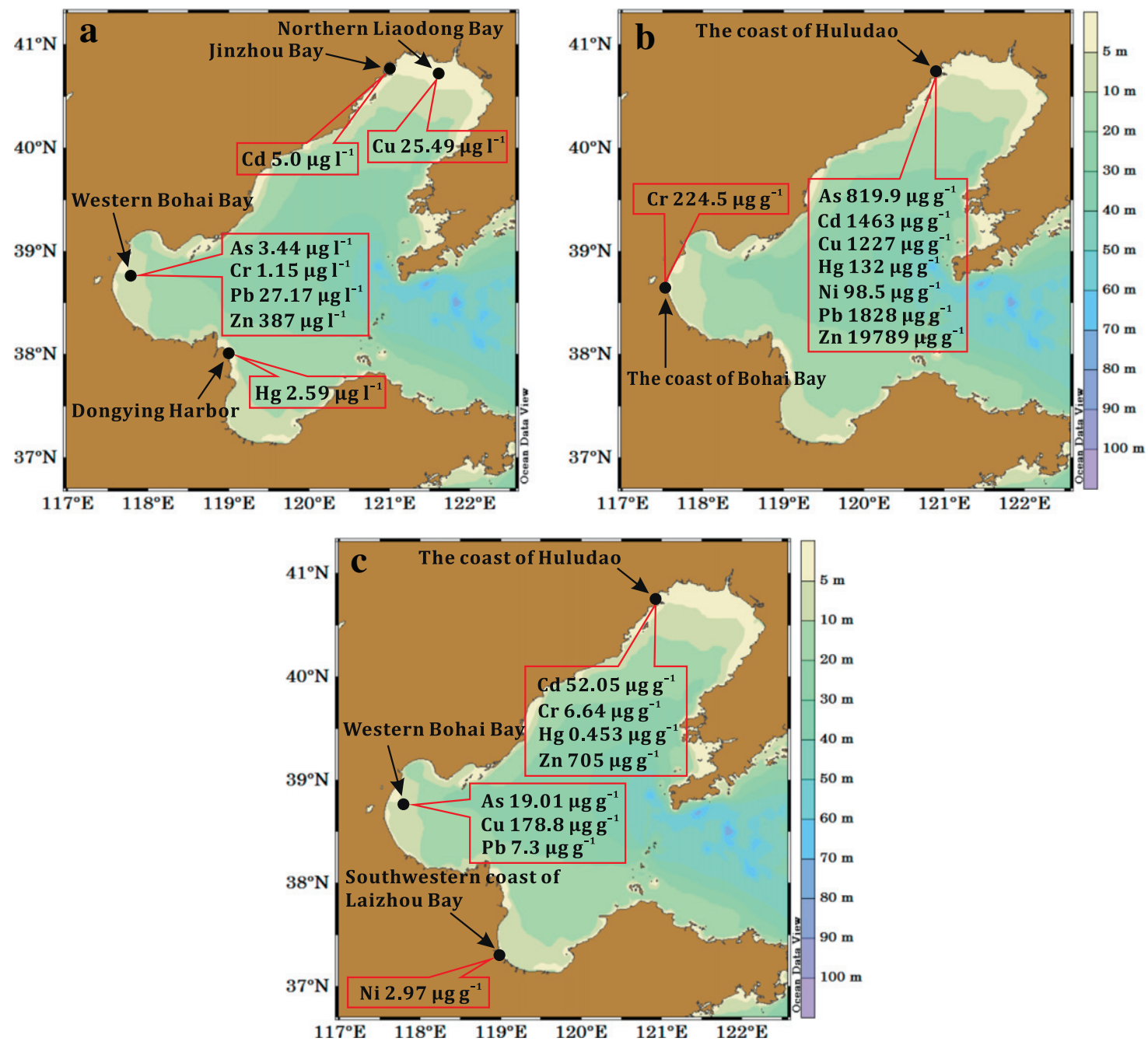

Fig. 2. Map of the distributions of the maximum levels of trace metals recorded in waters (a), sediments (b) and mollusks (c) in the Bohai Sea. 
Wan et al., 2008a). Shuangtaizihe River and Dalinghe River might be the key contributors to $\mathrm{Cu}$, Liaohe River might be the key contributor to $\mathrm{Pb}$ and Wulihe River might be the key contributor to $\mathrm{Zn}$ and $\mathrm{Cd}$ in the dissolved trace metal pool of the northern Liaodong Bay (Wan et al., 2008a). In October 2008, 67\% of upstream waters of rivers in the Northern Bohai Sea and the Yellow Sea could not be used for agriculture or recreation and $53 \%$ of downstream waters of these rivers could not be used as harbors or for industrial development based on the Chinese water quality standards for $\mathrm{Hg}$ (Luo et al., 2012). As for Cd and Zn, their mean concentrations in downstream waters were significantly higher than those in upstream waters along the North Bohai Sea (Luo et al., 2013). Besides, most downstream waters in that area were contaminated by $\mathrm{Zn}$ based on the study of Luo et al. (2013).

The Jinzhou Bay is a small cove in the northwest of the Liaodong Bay. Surrounded by the industrial base along its coast, the Jinzhou Bay has been seriously contaminated by the industrial effluents of petrochemical producers/companies, chlor-alkali facilities, and nonferrous metal smelting industries (Pan and Wang, 2012). It was reported that as early as the years 1987 and 1990 the concentrations of $\mathrm{Cd}, \mathrm{Cu}, \mathrm{Pb}$ and $\mathrm{Zn}\left(1.9,0.40,1.92,21.1 \mu \mathrm{g} \mathrm{l} \mathrm{l}^{-1}\right.$, respectively) in the waters of the Jinzhou Bay had already exceeded the upper limit of Grade I of the National Standard of China for Seawater Quality GB 3097-82, which was executed at that time (Ma et al., 1995). The average concentrations of trace metals in 2006 in the Jinzhou Bay were 1.98, 2.89, 1.16 and $30.64 \mu \mathrm{g} \mathrm{l}^{-1}$ for $\mathrm{Cd}, \mathrm{Cu}, \mathrm{Pb}$ and $\mathrm{Zn}$, respectively, all exceeding SWQ Grade I except for $\mathrm{Cu}$ (Wan et al., 2008b). But compared with the historic level of $\mathrm{Cu}$ in the Jinzhou Bay $\left(0.40 \mu \mathrm{g} \mathrm{l^{-1 }}\right.$ during 1987/1990), its concentration is still increased about 7 times. In September 2009, the average concentrations of $\mathrm{As}, \mathrm{Cd}, \mathrm{Cu}, \mathrm{Hg}, \mathrm{Pb}$ and $\mathrm{Zn}$ in the Jinzhou Bay were 2.19, 0.92, 3.06, 0.03, 0.61 and $11.87 \mu \mathrm{g} \mathrm{l}^{-1}$, respectively, and in $25 \%$ of the stations the concentrations of Cd were higher than SWQ Grade I and in all stations the concentrations of As were lower than that standard (Wang et al., 2012). From 1987 to 2009, trace metals in the Jinzhou Bay did not show much increase based on the data displayed in Table 1. The concentrations of dissolved metals in the Jinzhou Bay showed an apparent spatial pattern with the highest concentrations of $\mathrm{Cd}, \mathrm{Cu}, \mathrm{Pb}$ and $\mathrm{Zn}$ being found in the southwest of the bay which was near the outfalls of Huludao Zinc Plant and Bohai Ship Yard and the estuaries of Wulihe and Cishanhe rivers (Wan et al., 2008b; Wang et al., 2012).

\subsubsection{The situation of the Yellow River Estuary and its surrounding marine areas}

Although the freshwater run-off into the Bohai Sea is dominated by the Yellow River, a widely researched river home and abroad, biogeochemistry of trace metals in its estuary and adjacent marine areas is almost a blank in public literature.

A recent investigation carried out in May 2009 indicated that the concentrations of $\mathrm{As}, \mathrm{Cd}, \mathrm{Cu}, \mathrm{Hg}$ and $\mathrm{Pb}$ in the seawaters of the Yellow River Estuary and its surrounding marine areas rarely exceeded the upper limit of SWQ Grade I; Zn could be regarded as a pollutant, because its average concentration exceeded the ceiling of SWQ Grade I and fell into the range of SWQ Grade II (Tang et al., 2010). Spatially, their concentrations decreased seaward from littoral sea area and the Yellow River Estuary to the sea area far from the coast, which obviously reflected the effects of human activities, Yellow River discharge and land source pollution (Tang et al., 2010).

Compared with other marine areas of China, the concentrations of As, $\mathrm{Cd}, \mathrm{Cu}, \mathrm{Hg}, \mathrm{Pb}$ and $\mathrm{Zn}$ in the seawaters of the Yellow River Estuary and its surrounding marine area were lower than those of the heavily anthropogenically influenced Jiaozhou Bay, comparable with those of the Yangtze River Estuary and the Hangzhou Bay, but higher than those of some marginal seas such as the North Yellow Sea, the South Yellow Sea and the South China Sea (Cui et al., 1997; He et al., 2008; Ling, 2010; Sun et al., 2009; Tang et al., 2010; Tian et al., 2009; Yu, 2003).

\subsection{Trace metals in sediments}

Trace metals in sediments come from aqueous phase deposition via physical, chemical or biological ways; they can also be released through resuspension, dissolution and biodegradation. Trace metals in sediments are good indicators of historical and present environmental pollution and their concentration variations on short-time scales such as diurnal and weekly are generally smaller than in water columns, bringing extensive investigations of trace metals in the sediment phase of the Bohai Sea.

\subsubsection{The overall situation}

Like dissolved pools, investigations of trace metals in sediments covering the whole area of the Bohai Sea are hard to find in public literature. Related works were mainly carried out in the Bohai Bay and the Liaodong Bay, especially in their nearshore areas. Related works on the Laizhou Bay were relatively few. The elements As and $\mathrm{Ni}$ in sediments were reported to be less compared with other environmental quality criteria related trace metals (Table 2).

National Standard of China for Marine Sediment Quality (MSQ) GB 18668-2002 (SEPA, 2002), proposed by the State Oceanic Administration of People's Republic of China, is widely used to judge the potential risks of trace metals in marine sediments. This standard classifies the marine sediment into three classes based on the marine area's function and protection target. The Grade I marine sediment area is suitable for marine fishery, marine natural reserves, rare and endangered marine protected areas, aquaculture areas, bathing beach, sea sports or recreation areas where people contact seawaters directly and the industrial water area that has direct relation with human consumption. Grade II is appropriate for the general industrial water area and the coastal scenery tourist area. Grade III applies to the sea port waters and the ocean development area for special purposes.

Summarized from Table 2, Fig. $2 \mathrm{~b}$ shows that the maximum data of trace metals were recorded in sediments of the Bohai Sea. Clearly, the coastal areas of Huludao were polluted most seriously considering that the concentrations of $\mathrm{As}, \mathrm{Cd}, \mathrm{Cu}, \mathrm{Hg}, \mathrm{Ni}, \mathrm{Pb}$ and $\mathrm{Zn}$ in sediments of that area were much higher than those in the marine sediment quality guidelines (Table 2; Fig. 2b); the maximum concentration of $\mathrm{Cr}$ was recorded in the sediments of the coastal Bohai Bay near the Ziyaxin River estuary (Gao and Chen, 2012).

An investigation of $\mathrm{As}, \mathrm{Cd}, \mathrm{Hg}$ and $\mathrm{Pb}$ in the surface sediments of the whole Bohai Sea was conducted in 1998. Results showed that there was a severe contamination of $\mathrm{Cd}$ and $\mathrm{Hg}$ in the northern Liaodong Bay, an intermediate contamination of $\mathrm{Hg}$ in the coastal area of Qinhuangdao (Fig. 1) and a slight contamination of $\mathrm{Hg}$ in the southern Laizhou Bay (Chen et al., 2005). No recent literature on trace metals in sediments of the whole Bohai Sea has been found.

\subsubsection{The situation of the Bohai Bay}

The data of an 11-year monitoring program from 1997 to 2007 indicated that the mean concentrations of $\mathrm{Cd}, \mathrm{Cu}, \mathrm{Hg}, \mathrm{Pb}$ and $\mathrm{Zn}$ in the surface sediments of the Bohai Bay were all within the range for MSQ Grade I, but all higher than the corresponding background values of sediments in this area (Table 2; Zhan et al., 2010). This indicated that these metals did increase to some extent due to the influence of human activities, although their concentrations were still within relatively satisfactory levels. An investigation in spring 2008 showed that in the Bohai Bay, the concentrations of $\mathrm{Cd}$ and $\mathrm{Pb}$ were still lower than the MSQ Grade I but the concentrations of $\mathrm{Cu}$ and $\mathrm{Cr}$ were close to or slightly higher than that guideline (Table 2; Xu et al., 2012). A comparison of these two periods showed that the concentrations of $\mathrm{Cd}, \mathrm{Cu}$ and $\mathrm{Pb}$ increased obviously. In August 2008, a study was carried out in the southern Bohai Bay to get the knowledge of the potential contamination and environmental risks associated with heavy metals ( $\mathrm{Cd}, \mathrm{Cr}, \mathrm{Cu}, \mathrm{Ni}, \mathrm{Pb}$ and $\mathrm{Zn}$ ) (Hu et al., 2013a). It showed that the concentrations of trace metals $(\mathrm{Cd}, \mathrm{Cr}, \mathrm{Cu}, \mathrm{Pb}$ and $\mathrm{Zn})$ in the sediments 
Table 2

The summary of trace element concentrations ( $\mu \mathrm{g} \mathrm{g}^{-1}$ dry weight for all elements) in sediments of the Bohai Sea and relevant guideline values of different criteria.

\begin{tabular}{|c|c|c|c|c|c|c|c|c|c|c|c|c|}
\hline Location & Sampling date & Sampling size & & As & $\mathrm{Cd}$ & $\mathrm{Cr}$ & $\mathrm{Cu}$ & $\mathrm{Hg}$ & $\mathrm{Ni}$ & $\mathrm{Pb}$ & $\mathrm{Zn}$ & References \\
\hline \multirow[t]{6}{*}{ Bohai Bay } & \multirow{2}{*}{$\begin{array}{l}\text { May, every other } \\
\text { year from } 1997 \\
\text { to } 2007\end{array}$} & \multirow[t]{2}{*}{15} & Range & $\mathrm{na}^{\mathrm{a}}$ & $0.04-0.84$ & na & $7.2-44.0$ & $0.01-0.18$ & na & $5.9-97.0$ & $56.3-308.5$ & \multirow[t]{2}{*}{ Zhan et al. (2010) } \\
\hline & & & Mean \pm SD & na & $0.24 \pm 0.17$ & na & $28.1 \pm 8.1$ & $0.05 \pm 0.03$ & na & $21.2 \pm 18.3$ & $102.5 \pm 33.5$ & \\
\hline & & \multirow[t]{2}{*}{ na } & Range & na & na & $7.8-49$ & $18-32$ & na & $19.2-35.8$ & $16.6-27.4$ & $48-181$ & \multirow[t]{2}{*}{ Qin et al. (2006a) } \\
\hline & & & Mean & na & na & 25.4 & 25 & na & 26.9 & 22.1 & 88 & \\
\hline & \multirow[t]{2}{*}{ Apr., 2008} & \multirow[t]{2}{*}{27} & Max & na & 0.52 & 91.26 & na & na & na & 48.18 & na & \multirow[t]{2}{*}{ Xu et al. (2012) } \\
\hline & & & Mean & na & 0.30 & 83.66 & 35.32 & na & 39.99 & 30.60 & 97.27 & \\
\hline Bohai Bay background value & na & na & Mean & 13.0 & 0.112 & na & 25.63 & 0.05 & na & 16.55 & 74.61 & $\begin{array}{l}\text { Li and Hao (1992); } \\
\text { Li et al. (1994) }\end{array}$ \\
\hline Tianjin coastal region & May, 2000 & 10 & Mean & 16 & 0.19 & 82 & 32 & 0.15 & 47 & 29 & 112 & Li and Li (2008) \\
\hline Hebei coastal region & May, 2000 & 22 & Mean & 8 & 0.13 & 63 & 20 & 0.03 & 29 & 23 & 58 & Li and Li (2008) \\
\hline \multirow[t]{2}{*}{ NW coast of the Bohai Bay } & \multirow[t]{2}{*}{ Jun., 2003} & \multirow[t]{2}{*}{20} & Range & $6.40-16.50$ & $0.14-1.82$ & 18-191 & $11.4-27.3$ & $0.02-0.85$ & na & $17.5-34.9$ & $68.7-392.8$ & \multirow[t]{2}{*}{ Meng et al. (2008) } \\
\hline & & & Mean & 8.22 & 0.63 & 94.25 & 19.36 & 0.33 & na & 22.68 & 131.76 & \\
\hline \multirow[t]{2}{*}{ Estuary intertidal zone, W Bohai Sea } & \multirow[t]{2}{*}{ Oct., 2004} & \multirow[t]{2}{*}{12} & Range & na & $0.05-0.17$ & na & $9.82-38.99$ & $0.010-0.16$ & na & $0.81-4.97$ & $5.16-137.10$ & \multirow[t]{2}{*}{ Zhang et al. (2010a) } \\
\hline & & & Mean & na & 0.10 & na & 21.26 & 0.12 & na & 2.78 & 62.58 & \\
\hline \multirow[t]{2}{*}{ Intertidal Bohai Bay } & \multirow[t]{2}{*}{ May, 2008} & \multirow[t]{2}{*}{15} & Range & na & $0.05-0.19$ & $36.7-110$ & $7.9-46.7$ & na & $14.1-47.9$ & $18.8-39.1$ & $34.0-123$ & \multirow[t]{2}{*}{ Gao and Li (2012) } \\
\hline & & & Mean & na & 0.12 & 68.6 & 24.0 & na & 28.0 & 25.6 & 73.0 & \\
\hline \multirow[t]{2}{*}{ Coastal Bohai Bay } & \multirow[t]{2}{*}{ May, 2008} & \multirow[t]{2}{*}{42} & Range & na & $0.12-0.66$ & $60.1-225$ & $20.1-62.9$ & na & $23.4-52.7$ & $20.9-66.4$ & $55.3-457$ & Gao and Chen (2012) \\
\hline & & & Mean & na & 0.22 & 101.4 & 38.5 & na & 40.7 & 34.7 & 131 & \\
\hline Western Bohai Bay & Jul., 2007 & 5 & Mean $\pm S D$ & na & $1.29 \pm 0.12$ & $53.1 \pm 3.3$ & $27.9 \pm 1.8$ & na & $31.4 \pm 3.4$ & $20.5 \pm 1.0$ & $83.6 \pm 4.4$ & Feng et al. (2011) \\
\hline Port of Tianjin & Jul., 2007 & 3 & Mean \pm SD & na & $0.174 \pm 0.049$ & $61.5 \pm 9.5$ & $38.2 \pm 16.9$ & na & $36.1 \pm 3.8$ & $23.0 \pm 2.4$ & $109.9 \pm 29.5$ & Feng et al. (2011) \\
\hline & Sep., 2010 & 20 & Range & $2.19-5.29$ & $0.26-2.72$ & na & $3.32-11.95$ & $0.13-0.78$ & na & $2.23-50.81$ & na & Zhang et al. (2012) \\
\hline & & & Mean & 3.73 & 1.24 & na & 6.37 & 0.31 & na & 14.21 & na & \\
\hline Dagu Drainage Canal & Sep., 2010 & 16 & Range & $3.20-6.60$ & $2.93-22.69$ & na & $19.2-254.8$ & $0.07-4.03$ & na & $15.2-145.5$ & na & Zhang et al. (2012) \\
\hline & & & Mean & 4.87 & 11.25 & na & 69.9 & 0.87 & na & 55.9 & na & \\
\hline Yongdingxinhe River Estuary & Jul., 2007 & 2 & Mean \pm SD & na & $0.124 \pm 0.004$ & $51.9 \pm 3.5$ & $31.4 \pm 1.6$ & na & $31.2 \pm 3.1$ & $20.4 \pm 1.3$ & $92.9 \pm 2.3$ & Feng et al. (2011) \\
\hline Haihe River Estuary & Jul., 2007 & 2 & Mean $\pm S D$ & na & $0.173 \pm 0.009$ & $57.6 \pm 5.1$ & $29.5 \pm 3.5$ & na & $33.6 \pm 2.5$ & $25.6 \pm 0.7$ & $86.0 \pm 13.7$ & Feng et al. (2011) \\
\hline Yellow River Estuary & 2004-2005 & 27 & Mean & 9.0 & 0.1 & 19.7 & 19 & 0.04 & na & 13 & 31 & Wu et al. (2007) \\
\hline Southern Bohai Bay & Aug., 2008 & 119 & Range & na & $0.025-0.275$ & $10.2-84$ & $7.8-38.6$ & na & $16.5-43.7$ & $8.7-53.6$ & $40.5-126$ & Hu et al. (2013a) \\
\hline & & & Mean & na & 0.14 & 33.5 & 22.7 & na & 30.5 & 21.7 & 71.7 & \\
\hline Dongjiang Harbor, Tianjin & Mar, 2009 & 11 & Range & $10.43-23.88$ & $0.02-0.09$ & na & $13.00-26.82$ & $0.01-0.27$ & na & $0.62-6.39$ & $55.6-101.3$ & Guo et al. (2010) \\
\hline & & & Mean & 17.13 & 0.06 & na & 19.36 & 0.07 & na & 4.34 & 88.4 & \\
\hline Liaodong Bay & 2009 & 128 & Range & $3.1-20.3$ & na & $8.00-75.8$ & $5.7-37.1$ & $0.00-0.40$ & $7.0-40.5$ & $18.9-61.2$ & $14.5-145.0$ & Hu et al. (2013b) \\
\hline & & & Mean & 8.3 & na & 46.4 & 19.4 & 0.04 & 22.5 & 31.8 & 71.7 & \\
\hline Coastal areas of the $\mathrm{N}$ Bohai & Oct., 2008 & 35 & Range & $5.6-13$ & $0.05-0.83$ & $4.2-94$ & $0.53-35$ & $0.02-0.18$ & na & $9.5-49$ & $9.8-170$ & Luo et al. (2010) \\
\hline and Yellow Seas & & & Mean \pm SD & $8.5 \pm 1.9$ & $0.15 \pm 0.14$ & $47 \pm 22$ & $13 \pm 10$ & $0.028 \pm 0.028$ & na & $25 \pm 9.2$ & $60 \pm 40$ & \\
\hline
\end{tabular}




\begin{tabular}{|c|c|c|c|c|c|c|c|c|c|c|c|c|}
\hline \multirow{2}{*}{$\begin{array}{l}\text { Coastal watersheds along } \\
\text { the N Bohai Sea }\end{array}$} & \multirow[t]{2}{*}{ Oct., 2008} & \multirow[t]{2}{*}{35} & Range & na & na & na & na & $0.017-0.18$ & na & na & na & \multirow[t]{2}{*}{ Luo et al. (2012) } \\
\hline & & & Mean $\pm S D$ & na & na & na & na & $0.027 \pm 0.028$ & na & na & na & \\
\hline $\begin{array}{l}\text { Upstream regions of coastal } \\
\text { watersheds along the N Bohai Sea }\end{array}$ & Oct., 2008 & 17 & $\mathrm{GM} \pm \mathrm{SD}^{\mathrm{b}}$ & na & $0.13 \pm 0.18$ & na & na & na & na & na & $50 \pm 39$ & Luo et al. (2013) \\
\hline $\begin{array}{l}\text { Downstream regions of coastal } \\
\text { watersheds along the N Bohai Sea }\end{array}$ & Oct., 2008 & 12 & $\mathrm{GM} \pm \mathrm{SD}$ & na & $0.11 \pm 0.082$ & na & na & na & na & na & $34 \pm 33$ & Luo et al. (2013) \\
\hline Liaohe River Estuary & Before 1985 & na & Mean & na & 0.123 & na & 13.85 & na & na & 9.20 & 46.80 & Zhou et al. (2004) \\
\hline Liaoning coastal region & May, 2000 & 12 & Mean & 13 & 0.44 & 64 & 24 & 0.08 & 34 & 29 & 96 & Li and Li (2008) \\
\hline \multirow[t]{2}{*}{ River mouths in the Liaodong Bay } & Mar., 2003 & 22 & Range & na & $0-9.7$ & na & $5.2-49.3$ & na & na & $6.7-130.6$ & $47.9-322.3$ & Zhou et al. (2004) \\
\hline & & & Mean & na & 1.16 & na & 17.6 & na & na & 23.9 & 105.3 & \\
\hline \multirow[t]{2}{*}{ Shuangtaizihe River Estuary ${ }^{c}$} & Jul., 2008 & 2 & Range & na & $0.07-0.32$ & $26.5-65.0$ & $9.9-27.2$ & na & $12.3-40.8$ & $15.1-25.9$ & $30.3-85.0$ & Liu et al. (2011a) \\
\hline & & & Mean & na & 0.21 & 50.5 & 19.9 & na & 25.1 & 20.8 & 61.4 & \\
\hline \multirow[t]{2}{*}{ Wulihe River } & May, 2005 & 10 & Range & na & $1.03-30.9$ & na & $31.3-107$ & $0.151-15.4$ & na & $48.7-198$ & $144-2077$ & Zheng et al. (2008) \\
\hline & & & Mean & na & 7.947 & na & 56.63 & 8.668 & na & 80.5 & 525.2 & \\
\hline \multirow[t]{2}{*}{ Cishanhe River } & May, 2005 & 6 & Range & na & $0.374-1463$ & na & $36.9-1072$ & $0.344-132$ & na & $32.7-1551$ & $132-19,789$ & Zheng et al. (2008) \\
\hline & & & Mean & na & 250.3 & na & 217 & 33.07 & na & 454.1 & 5595 & \\
\hline \multirow[t]{2}{*}{ Liangshanhe River } & May, 2005 & 4 & Range & na & $1.25-19.4$ & na & $29.0-106$ & $0.22-5.39$ & na & $59.3-164$ & $114-508$ & Zheng et al. (2008) \\
\hline & & & Mean & na & 9.73 & na & 73.08 & 1.59 & na & 104.9 & 450.9 & \\
\hline \multirow[t]{6}{*}{ Jinzhou Bay } & na & na & Range & na & $2.6-488.2$ & na & $27-619$ & $14.6-41.1$ & $36.4-98.5$ & $29.8-1650$ & $180-10,447$ & Fan et al. (2006) \\
\hline & Sep., 2006 & 14 & Range & $20.4-820$ & $4.8-910$ & $44.0-72.4$ & $9.3-1227$ & na & na & $21.8-1828$ & $89.2-13,933$ & Zhang et al. (2008) \\
\hline & & & Mean & 396.5 & 248.1 & 60.6 & 417 & na & na & 753 & 6419 & \\
\hline & Aug., 2007 & 1 & Max & na & 64 & na & 400 & na & na & 460 & na & Wang et al. (2010b) \\
\hline & Oct., 2009 & 25 & Range & na & $7.91-105.31$ & na & $24.45-327.5$ & na & $26.29-85.99$ & $29.17-523.5$ & $168.1-2506$ & Li et al. (2012) \\
\hline & & & Mean $\pm S D$ & na & $26.81 \pm 22.23$ & na & $74.11 \pm 68.54$ & na & $43.47 \pm 11.92$ & $124.0 \pm 114.7$ & $689.4 \pm 568.5$ & \\
\hline Southern sea area of the & na & 35 & Range & $6.29-23.2$ & na & $32.3-128$ & $13.9-39.9$ & $0.035-0.323$ & na & $5.17-51.10$ & $56.0-238$ & Wang et al. (2013) \\
\hline Huludao City & & & Mean & 12.0 & na & 75.0 & 25.9 & 0.169 & na & 32.20 & 144 & \\
\hline \multirow[t]{2}{*}{ Laizhou Bay } & Aug., 2007 & 42 & Range & $9.6-17.9$ & $0-0.025$ & $34.0-91.1$ & $2.9-26.4$ & $0.02-0.115$ & $7.6-33.9$ & $11.6-33.1$ & $34.3-93.4$ & Hu et al. (2011) \\
\hline & & & Mean & 13.1 & 0.081 & 57.1 & 13.3 & 0.053 & 19.4 & 20.2 & 59.4 & \\
\hline Yangtze River Estuary & Apr. \& Aug., 2005 & 59 & Mean & na & 0.26 & 78.9 & 30.7 & na & 31.8 & 27.3 & 94.3 & Zhang et al. (2009) \\
\hline Pearl River Estuary & na & na & Mean & na & na & 86.3 & 39.4 & na & na & 53.3 & 130.4 & Huang et al. (2006) \\
\hline ERL & & & & 8.2 & 1.2 & 81 & 34 & 0.15 & 20.9 & 46.7 & 150 & Long et al. (1995) \\
\hline ERM & & & & 70 & 9.6 & 370 & 270 & 0.71 & 51.6 & 218 & 410 & Long et al. (1995) \\
\hline TEL & & & & 7.24 & 0.68 & 52.3 & 18.7 & 0.13 & 15.9 & 30.2 & 124 & MacDonald et al. (1996) \\
\hline PEL & & & & 41.6 & 4.21 & 160 & 108 & 0.7 & 42.8 & 112 & 271 & MacDonald et al. (1996) \\
\hline $\begin{array}{l}\text { Background value in the Bohai } \\
\text { Sea and adjacent estuaries }\end{array}$ & & & Mean & 10 & 0.069 & 60 & 19 & 0.050 & na & 11.5 & 57 & $\begin{array}{l}\text { Feng et al. (2003); } \\
\text { Li and Liu (1994) }\end{array}$ \\
\hline Grade I $^{\mathrm{d}}$ & & & & $\leq 20$ & $\leq 0.5$ & $\leq 80$ & $\leq 35$ & $\leq 0.2$ & na & $\leq 60$ & $\leq 150$ & SEPA (2002) \\
\hline Grade II ${ }^{\mathrm{e}}$ & & & & $\leq 65$ & $\leq 1.5$ & $\leq 150$ & $\leq 100$ & $\leq 0.5$ & na & $\leq 130$ & $\leq 350$ & SEPA (2002) \\
\hline
\end{tabular}

a na: not available.
b $\mathrm{GM} \pm \mathrm{SD}$ : geometic mean \pm standard deviation.

$\begin{array}{ll} & \\ \text { c } & \text { SM } \pm \text { SD: geometiment core samples. }\end{array}$

d Grade I: National Standard of China for Marine Sediment Quality GB 18668-2002 Grade I.

e Grade II: National Standard of China for Marine Sediment Quality GB 18668-2002 Grade II. 
generally met the MSQ Grade I (Table 2). The northwestern coast of the Bohai Bay was faced with the most serious threat from anthropogenic activities. Average values of $\mathrm{Cd}, \mathrm{Hg}, \mathrm{Pb}$ and $\mathrm{Zn}$ in that area exceeded those of the other areas of the Bohai Bay (Table 2; Meng et al., 2008). Besides, there was evidence that the surface sediments of some regions in the inintertidal Bohai Bay were contaminated by some metals (Gao and Li, 2012; Li and Li, 2008; Zhang et al., 2012). The concentrations of As, $\mathrm{Cr}, \mathrm{Cu}$ and $\mathrm{Hg}$ exceeded the upper limit of MSQ Grade I (Table 2).

Besides comparing with the Marine Sediment Quality, other marine sediment assessment methods like Effects Range-Low (ERL) and Effects Range-Median (ERM) guidelines, enrichment factor (EF), geoaccumulation index $\left(I_{\text {geo }}\right)$ and mean ERM quotient were also used to evaluate the Bohai Bay's situation. These assessment methods have not only their own characteristics but also the function like verifying and supplementing mutually. Gao and Chen (2012) analyzed the concentrations of $\mathrm{Cd}, \mathrm{Cr}, \mathrm{Cu}, \mathrm{Ni}, \mathrm{Pb}$ and $\mathrm{Zn}$ in 42 surface sediment samples collected from the northwestern coast of the Bohai Bay covering its nearshore zone and the major rivers it is connected with, and the Effects Range-Low (ERL) and Effects Range-Median (ERM) guidelines (Table 2; Long et al., 1995) were used to judge the potential environmental risks of these trace metals. ERL guideline values indicate the concentrations of trace metals below which adverse effects on biota are rarely observed in sediments and ERM guideline values indicate the concentrations of trace metals above which adverse effects on biota are frequently observed in sediments (Long et al., 1995). The results suggested that no sites exceeded the ERL guideline for Cd, $14 \%$ of sites were below the ERL guideline for $\mathrm{Cr}$, $33 \%$ of sites were below the ERL guideline for $\mathrm{Cu}, 86 \%$ of sites were below the ERL guideline for $\mathrm{Zn}$, and $95 \%$ of sites were below the ERL guideline for $\mathrm{Pb}$; whereas $\mathrm{Ni}$ at all sites exceeded the ERL guideline and its value at one site was even slightly higher than the ERM guideline, which indicated a potential harm to benthic organisms; the $\mathrm{Zn}$ value at one site also exceeded the ERM guideline (Gao and Chen, 2012).

Similar to ERL and ERM, the threshold effects level (TEL) and probable effects level (PEL) of some substances with potential environmental risks were derived to aid the interpretation of sediment chemistry data (Table 2; MacDonald et al., 1996). Generally, the TELs have been used to identify relatively uncontaminated samples that pose a limited risk of toxicity; the PELs have been used to identify those samples in which chemical concentrations were sufficiently elevated to warrant further evaluation (Long et al., 1998). According to this criterion, $\mathrm{Cd}$ and $\mathrm{Zn}$ in all types of surface sediments, and $\mathrm{Cr}, \mathrm{Cu}$ and $\mathrm{Pb}$ in the sand and silty sand surface sediments of the intertidal Bohai Bay could be regarded as relatively uncontaminated that pose only a limited risk of toxicity (Gao and Li, 2012). The surface sediment texture of the northern part of the northwestern intertidal Bohai Bay was mainly clayey silt, and that of the southern part of the northwestern intertidal Bohai Bay was mainly sand and silty sand (Gao and Li, 2012).

Among $\mathrm{Cd}, \mathrm{Cr}, \mathrm{Cu}, \mathrm{Ni}, \mathrm{Pb}$ and $\mathrm{Zn}, \mathrm{Cr}$ was more accumulated in the surface sediments of the coastal Bohai Bay than the others, which could be reflected by their enrichment factor (EF) values; based on the criteria in Hakanson (1980), the pollution potential of $\mathrm{Cu}, \mathrm{Pb}$ and $\mathrm{Zn}$ was negligible to low contamination for their $\mathrm{EF}$ values were $<2$ except in some riverine and several clayey silt intertidal sediments (Gao and Chen, 2012; Gao and Li, 2012). Guo et al. (2010) reported that the order of EFs of trace metals in the sediments of the Dongjiang Harbor, Tianjin was $\mathrm{As}>\mathrm{Zn}>\mathrm{Cu}>\mathrm{Hg}>\mathrm{Pb}>\mathrm{Cd}$. According to Müller's classification (Müller, 1969), the geoaccumulation index $\left(I_{\text {geo }}\right)$ of $\mathrm{Cd}, \mathrm{Cr}, \mathrm{Cu}, \mathrm{Ni}, \mathrm{Pb}$ and $\mathrm{Zn}$ in sand and silty sand sediments of the intertidal Bohai Bay presented values falling into the unpolluted class, and the $I_{\text {geo }}$ values of the studied metals in clayey silt sediments fell into unpolluted to moderately polluted class (Gao and Li, 2012).

The result of the mean ERM quotient (Carr et al., 1996) indicated that the combination of $\mathrm{Cd}, \mathrm{Cr}, \mathrm{Cu}, \mathrm{Ni}, \mathrm{Pb}$ and $\mathrm{Zn}$ in the riverine and nearshore surface sediments of the coastal Bohai Bay might have a $21 \%$ probability of being toxic (Gao and Chen, 2012); according to the mean PEL quotient (Long et al., 1998), the combination of $\mathrm{Cd}, \mathrm{Cr}, \mathrm{Cu}$, $\mathrm{Ni}, \mathrm{Pb}$ and $\mathrm{Zn}$ in the surface sediments of the intertidal Bohai Bay may also have a $21 \%$ probability of being toxic (Gao and Li, 2012).

Rivers were supposed to be the source of pollution of coastal seas, while trace metals in the sediments of some estuaries in the Bohai Bay did not show relatively higher concentrations compared with other areas of the Bohai Bay or the Bohai Sea. The contents of $\mathrm{Cd}, \mathrm{Cu}, \mathrm{Hg}, \mathrm{Pb}$ and $\mathrm{Zn}$ in the intertidal surface sediments of the Yongdingxinhe River Estuary did not exceed the ambient background values and were lower than the other areas of the Bohai Sea (Zhang et al., 2010a). The contents of trace metals in the sediments from the Haihe River Estuary were comparable to their background values in the sediments of the Bohai Bay and lower than those of the sediments from the northwestern coast of the Bohai Bay (Table 2; Feng et al., 2011). Xu et al. (2012) also found that the concentrations of trace metals in the surface sediments increased and then decreased from the Haihe River Estuary to open seas. The values of trace metals in the sediments of the Yellow River Estuary were all lower than the Bohai Bay background values (Table 2; Wu et al., 2007). Besides, the Yellow River Estuary was the least polluted by trace metals compared with the Yangtze River Estuary and the Pearl River Estuary (Table 2). However, in the sediments of the areas near Daguhe River and Qihe River mouths, the contents of $\mathrm{Cd}, \mathrm{Pb}$ and $\mathrm{Zn}$ were higher than their corresponding environmental background values (Qin et al., 2006a, 2006b). There is no doubt that river source is one of the important sources of trace metals in the Bohai Sea. The reason that concentrations of trace metals in some estuaries are lower than those of other areas of the Bohai Bay or the Bohai Sea may be the special environment of estuary, such as complex hydrodynamics, adsorption and resolution, the gradual change of chemical environment and so on.

The research of Gao and Chen (2012) and Gao et al. (2012) showed that, in the surface sediments of coastal Bohai Bay, organic matter was a key determinant of the spatial distribution of some trace metals like $\mathrm{Cd}$, $\mathrm{Pb}$ and $\mathrm{Zn}$ and a large part of the terrestrial organic matter transported by the rivers that discharge into the Bohai Bay was deposited in riverine sediments before the rivers enter the sea. This may be one of the reasons that concentrations of trace metals in sediments from some areas around the estuaries of the Bohai Bay were not as high as some may have expected. Complicated hydraulic conditions in the estuary may also in part determine the distribution of trace metals in sediments of these areas.

Besides the riverine source, atmospheric deposition was thought to be another important source of trace metals in the sediments of the Bohai Bay (Meng et al., 2008), although there was a lack of supporting data. The combined effects of riverine and atmospheric sources may be responsible for higher concentrations of some trace metals in sediments occurring not only along the shoreline but also in the inner part of the Bohai Bay (Zhan et al., 2010).

The study of core sediments in the Daguhe River Estuary in September 2010 showed that from early 1950s to early 1960s, among $\mathrm{As}, \mathrm{Cd}, \mathrm{Cu}, \mathrm{Hg}$ and $\mathrm{Pb}, \mathrm{Hg}$ contributed much to the Daguhe River Estuary's ecological risk increase, while in recent 3 years, the increasing $\mathrm{Cd}$ and $\mathrm{Hg}$ contributed increasingly to its rapid increase of ecological risk (Zhang et al., 2012).

\subsubsection{The situation of the Liaodong Bay}

Literature reflecting the conditions of trace metals in sediments of the whole Liaodong Bay marine area is not much. A newly published literature assessed trace metals in the surface sediments of Liaodong Bay. The concentrations of $\mathrm{As}, \mathrm{Cr}, \mathrm{Cu}, \mathrm{Hg}, \mathrm{Ni}, \mathrm{Pb}$ and $\mathrm{Zn}$ in that area generally met the MSQ Grade I (Hu et al., 2013b). Most investigations were carried out in the coastal Liaodong Bay (Liu et al., 2011a; Luo et al., 2010, 2012, 2013; Zhou et al., 2004). An investigation of 2003 indicated that the average concentrations of $\mathrm{Cd}, \mathrm{Cu}, \mathrm{Pb}$ and $\mathrm{Zn}$ in the estuarine surface sediments of the major rivers around the Liaodong Bay were all significantly higher than those of 1980s (Zhou et al., 
2004). The reports of $\mathrm{Li}$ and $\mathrm{Li}$ (2008) and Liu et al. (2011a) also confirmed this fact after comparing their data with those of the 1980s (Table 2). Three recent publications reported the situations of As, Cd, $\mathrm{Cr}, \mathrm{Cu}, \mathrm{Hg}, \mathrm{Pb}$ and $\mathrm{Zn}$ in coastal surface sediments covering the entire coastline of the Liaodong Bay and the northern coastline of the Yellow Sea in the Liaodong Peninsula based on the study in October 2008 (Luo et al., 2010, 2012, 2013). Although the concentrations of some elements exceeded the corresponding background values and apparently accumulated at certain places, none of the mean concentrations of these metals in this report exceeded the upper limit of MSQ Class I (Luo et al., 2010, 2012, 2013; Table 2). Their concentrations were unlikely to be acutely toxic, but chronic exposures could be expected to cause adverse effects on benthic invertebrates at about $1 / 3$ of the studied sites. The degree of contamination of these elements decreased in the sequence of $\mathrm{Pb}>\mathrm{Cd}>\mathrm{Zn}>\mathrm{Cr}>\mathrm{Cu}>\mathrm{As}>\mathrm{Hg}$ (Luo et al., 2010).

The history of trace metal pollution in the sediments of the Liaodong Bay could be traced back to late 1970s, since which time the concentrations and burial fluxes of $\mathrm{Zn}, \mathrm{Pb}, \mathrm{Cd}$, and $\mathrm{Hg}$ increased abruptly (Xu et al., 2009a, 2009b). The EF values of $\mathrm{Cd}, \mathrm{Hg}, \mathrm{Zn}$ and $\mathrm{Pb}$ in surface sediments were more than $30,10,7$ and 3.5 , respectively. Coincident with the increase of trace metal contents, the decreasing trend of ${ }^{206} \mathrm{~Pb} /{ }^{207} \mathrm{~Pb}$ ratio indicated that $\mathrm{Pb}$ in surface sediments mainly came from anthropogenic activities (Xu et al., 2009b).

Huludao City is located along the coast of the Jinzhou Bay in the northwestern coast of the Liaodong Bay (Fig. 1), and it is a region strongly affected by industrialization. Wulihe, Cishanhe and Lianshanhe Rivers flow through Huludao City.

The southern sea area of the Huludao City might be polluted by heavy metals considering its close location to the Jinzhou Bay (Wang et al., 2013). The serious contamination of trace metals in the sediments of Jinzhou Bay and the rivers it connects with has been reported by many researchers (Fan et al., 2008; Li et al., 1996; Luo et al., 2010, 2012; Ma et al., 1995; Wang et al., 2010b; Zhang et al., 2008; Zheng et al., 2008; Zhou et al., 2004). Hg was the major toxicity contributor which accounted for $53.3-93.2 \%$ and $7.9-54.9 \%$ of the total toxicity of trace metals in the sediments of Wulihe and Lianshanhe Rivers, respectively, followed by $\mathrm{Cd}$; $\mathrm{Cd}$ was the major toxicity contributor in the sediments of Cishanhe River, accounting for $63.2-66.9 \%$ of the total toxicity of trace metals (Zheng et al., 2008). Luo et al. (2012) also found the highest concentration of $\mathrm{Hg}$ in coastal watersheds located along the northern Bohai Sea was in the upstream sediments of Wulihe River in Huludao. The contamination of $\mathrm{Hg}$ in sediments of Wulihe River originated from the chlor-alkali producing industry; the contamination of $\mathrm{Pb}, \mathrm{Cd}, \mathrm{Zn}$ and $\mathrm{Cu}$ was mainly derived from atmospheric deposition and small unknown pollution sources (Zheng et al., 2008). The contamination of trace metals in Cishanhe River sediments was mainly derived from the Huludao Zinc Plant, and in Lianshanhe River sediments it was primarily from the atmospheric deposition, sewage wastewater and small unknown pollution sources (Zheng et al., 2008).

After flowing through Huludao City, Wulihe, Cishanhe and Lianshanhe Rivers run into the Jinzhou Bay, making the Jinzhou Bay the most polluted marine area in the Bohai Sea since the late 1970s and early 1980s (Fan et al., 2006, 2008; Li et al., 1996; Ma et al., 1995; Wang et al., 2010b; Zhang et al., 2008). The average concentrations of As, $\mathrm{Cd}, \mathrm{Cu}$ and $\mathrm{Pb}$ recorded in the surface sediments of the Jinzhou Bay were several times to nearly 500 times higher than the upper limit of MSQ Grade I reported in recent work (Li et al., 2012; Wang et al., 2010b; Zhang et al., 2008). With high concentrations and high proportion of bioavailable trace metals, the Jinzhou Bay's ecological risk is very high (Fan et al., 2008).

\subsubsection{Trace metals in sediments of the Laizhou Bay}

The Laizhou Bay is an important area for fish and shrimp spawning and nursery in China. Li et al. (1996) indicated that the Laizhou Bay was one of the least polluted major bays in the Bohai Sea before the early 1980s. In recent years, like other parts of the Bohai Sea, the Laizhou Bay has been faced with more and more pressure from anthropogenic activities. Liu et al. (2004a) reported that the trace metal contents in the upper $5-10 \mathrm{~cm}$ sediments increased greatly.

However, a survey in 2007 showed that all the average concentrations of $\mathrm{As}, \mathrm{Cd}, \mathrm{Cr}, \mathrm{Cu}, \mathrm{Hg}, \mathrm{Ni}, \mathrm{Pb}$ and $\mathrm{Zn}$ in surface sediments of the Laizhou Bay did not exceed MSQ Class I (Table 2), among which $\mathrm{Cd}, \mathrm{Cr}, \mathrm{Cu}, \mathrm{Ni}$ and $\mathrm{Zn}$ were not enriched, and were mainly derived from the natural weathering of rocks (Hu et al., 2011). On the other hand, As and $\mathrm{Pb}$ were moderately enriched and their concentrations were influenced by both natural and anthropogenic sources. Hg was derived chiefly from the anthropogenic sources. The concentrations of As and Ni in surface sediments of the Laizhou Bay may occasionally cause adverse ecological effects as they both fell in the range between the guideline values of ERL and ERM (Hu et al., 2011). The concentrations of $\mathrm{Cd}, \mathrm{Cr}, \mathrm{Cu}, \mathrm{Hg}, \mathrm{Pb}$ and $\mathrm{Zn}$ in most parts of the Laizhou Bay were lower than their corresponding ERL guidelines, indicating that these metals may not cause adverse ecological effects. As a whole, more attention should be paid to As and $\mathrm{Ni}$ in the surface sediments of the Laizhou Bay.

The concentrations of trace metals in the surface sediments of the Laizhou Bay presented a certain spatial pattern. In the east-west direction, these trace metals decreased gradually from the coast toward the center of the bay; in the north of the bay the concentrations of the trace metals were generally higher than those in the south (Hu et al., 2011). The Yellow River and Xiaoqinghe River are the two major rivers running into the Laihzou Bay. The quality of surface sediments in the northwestern and outer areas of the Yellow River Estuary was relatively poor, indicating that the Yellow River may be a major pollution source of trace metals in the Laizhou Bay, while that was not the condition for the Xiaoqinghe River (Hu et al., 2011).

\subsubsection{Fractionation of trace metals}

The aforementioned trace metals in the sediments of the Bohai Sea are all in total concentrations. In fact, each trace metal exists in many forms like acid soluble, reducible, oxidizable and residual (Gao and $\mathrm{Li}, 2012$ ). Different existing forms of trace metals have different environmental influence because of their different bioavailability. The concentrations of trace metals in high-bioavailability forms should be understood to know their real environmental impact.

Gao and Chen (2012) and Gao and Li (2012) applied a four-step sequential extraction procedure to study the fractionation of trace metals in surface sediments of the coastal Bohai Bay covering its intertidal and sublittoral zones and the major rivers it connects with. The same technique was also applied to assess the mobility of trace metals in sediments of other marine areas in China such as the Daya

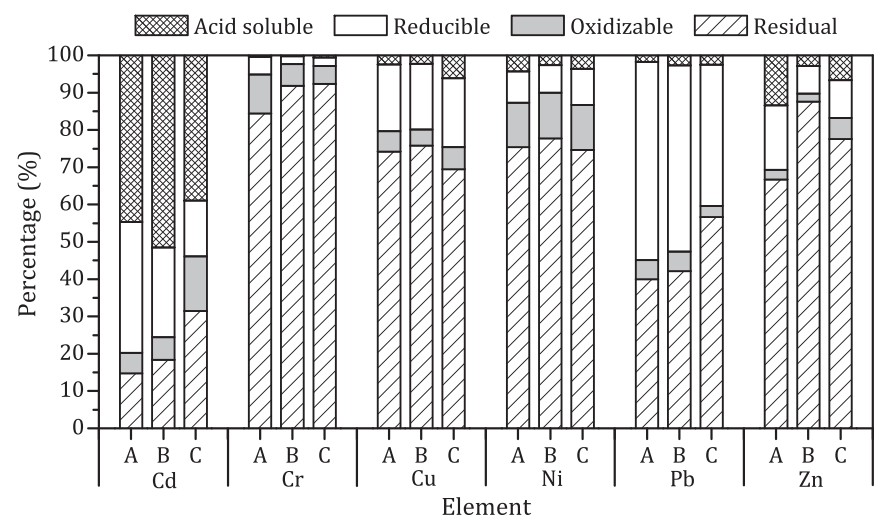

Fig. 3. The distributions of trace metals in different geochemical fractions of surface sediments from the coastal Bohai Bay based on the reports of Gao and Chen (2012) and Gao and Li (2012). A, riverine sediments; B, nearshore marine sediments; C, intertidal sediments. 
Table 3

The summary of trace element concentrations ( $\mu \mathrm{g} \mathrm{g}^{-1}$ wet weight for all elements except noted) in organisms of the Bohai Sea and relevant guideline values of different criteria.

\begin{tabular}{|c|c|c|c|c|c|c|c|c|c|c|c|c|c|}
\hline Location & Sampling date & Classification & & As & $\mathrm{Cd}$ & $\mathrm{Cr}$ & $\mathrm{Cu}$ & $\mathrm{Hg}^{\mathrm{a}}$ & $\mathrm{MeHg}^{\mathrm{b}}$ & $\mathrm{Ni}$ & $\mathrm{Pb}$ & $\mathrm{Zn}$ & Reference \\
\hline \multirow[t]{4}{*}{ Bohai Sea } & Jul. to Aug., 2002 & Mollusks & Range & $0.53-19.01$ & $0.14-52.05$ & $0.19-3.24$ & $1.06-109.6$ & $0.01-0.31$ & na & $0.09-2.97$ & $0.06-0.75$ & $5.09-431.0$ & Wang et al. (2005a) \\
\hline & Jul. to Aug., 2003 & Mollusks & Range & $0.63-13.99$ & $0.13-32.18$ & $0.13-1.36$ & $1.08-146.85$ & $0.01-0.10$ & na & $0.06-1.67$ & $0.02-1.33$ & $5.69-550.1$ & Wang et al. (2005a) \\
\hline & $2002-2003$ & Mollusks & Range & $\mathrm{na}^{\mathrm{c}}$ & na & na & na & $0.005-0.199$ & nd -0.033 & na & na & na & Wang et al. (2005b) \\
\hline & & Benthic mussels & Range & $0.292-12.15$ & $0.27-6.5$ & na & na & $0.006-0.108$ & na & na & $0.033-0.895$ & na & Liu et al. (2007) \\
\hline \multirow{2}{*}{$\begin{array}{l}\text { Coastal region of the Bohai } \\
\text { and Yellow Seas }\end{array}$} & Jul. to Dec., 1990 & Mollusks & Range & na & $0.04-8.56$ & $0.02-6.64$ & $10.48-178.8$ & na & na & na & $0.04-4.15$ & $4.10-178.4$ & $\mathrm{He}(1996)$ \\
\hline & & & Mean & na & 1.15 & 0.70 & 5.34 & na & na & na & 0.36 & 20.2 & \\
\hline \multirow{4}{*}{$\begin{array}{l}\text { Coastal watersheds along } \\
\text { the N Bohai Sea }\end{array}$} & Oct., 2008 & Carp & Range & na & na & na & na & $0.031-4.0$ & $0.030-0.066$ & na & na & na & Luo et al. (2012) \\
\hline & & & Mean $\pm S D$ & na & na & na & na & $0.47 \pm 1.2$ & $0.44 \pm 1.2$ & na & na & na & \\
\hline & & Crab & Range & na & na & na & na & $0.032-3.8$ & $0.012-3.3$ & na & na & na & \\
\hline & & & Mean $\pm S D$ & na & na & na & na & $0.67 \pm 1.2$ & $0.56 \pm 1.0$ & na & na & na & \\
\hline $\begin{array}{l}\text { Upstream regions of coastal } \\
\text { watersheds along the } \\
\mathrm{N} \text { Bohai Sea }\end{array}$ & Oct., 2008 & Carp & $\mathrm{GM} \pm \mathrm{SD}^{\mathrm{d}}$ & na & $0.0036 \pm 0.042$ & na & na & na & na & na & na & $38 \pm 15$ & Luo et al. (2013) \\
\hline $\begin{array}{l}\text { Downstream regions of } \\
\text { coastal watersheds } \\
\text { along the N Bohai Sea }\end{array}$ & Oct., 2008 & Crab & $\mathrm{GM} \pm \mathrm{SD}$ & na & $0.020 \pm 0.10$ & na & na & na & na & na & na & $10 \pm 6.7$ & Luo et al. (2013) \\
\hline \multirow[t]{7}{*}{ Bohai Bay } & Apr. and Oct., 1981 & Fish & Range & na & $0.21-2.10$ & na & $0.35-7.55$ & na & na & na & $0.50-5.00$ & $14.3-172$ & Liu et al. (1983) \\
\hline & & & Mean & na & 0.21 & na & 2.12 & na & na & na & 1.27 & 43.3 & \\
\hline & & Crustacea & Range & na & $0.10-0.51$ & na & $0.59-6.47$ & na & na & na & $0.30-3.00$ & $20-51.8$ & \\
\hline & & & Mean & na & 0.18 & na & 2.73 & na & na & na & 1.82 & 32.5 & \\
\hline & & Mollusks & Range & na & $0.18-2.45$ & na & $0.42-5.39$ & na & na & na & $0.60-7.30$ & $20.6-158.4$ & \\
\hline & & & Mean & na & 0.75 & na & 1.70 & na & na & na & 1.85 & 50.4 & \\
\hline & & Polychaeta & Mean & na & 0.18 & na & 0.92 & na & na & na & 2.90 & 25.3 & \\
\hline Yingkou & Jul. to Aug., 2002 & Rapana venosa & Mean & na & 4.71 & na & 33.75 & 0.0605 & na & 0.28 & 0.11 & 57.65 & $\begin{array}{l}\text { Liang et al. } \\
(2003,2004)\end{array}$ \\
\hline \multirow[t]{3}{*}{ Jinzhou Bay } & 1987-1990 & Fish & Mean & na & na & na & na & na & na & na & na & na & Ma et al. (1995) \\
\hline & & Crustacea & Mean & na & 0.18 & na & 42 & 0.17 & na & na & 0.04 & 127.5 & \\
\hline & & Mollusks & Mean & na & 3.16 & na & 2.17 & 0.22 & na & na & 0.26 & 53.9 & \\
\hline Huludao & Jul. to Aug., 2002 & Rapana venosa & Mean & na & 30.61 & na & 172.25 & 0.453 & na & 0.14 & 0.09 & 705 & $\begin{array}{l}\text { Liang et al. } \\
(2003,2004)\end{array}$ \\
\hline \multirow[t]{3}{*}{ Coastal Huludao } & Jun., 1999 & Fish & Range & $0.24-2.14$ & $0.069-0.62$ & na & $0.8-4.70$ & $0.00048-0.00139$ & na & na & $0.013-0.265$ & $12.29-30.8$ & Yue and Shi (2001) \\
\hline & & Crustacea & Range & $1.71-17.21$ & $0.595-89.28$ & na & $4.99-44.84$ & $0.00022-0.0173$ & na & na & $0.038-1.427$ & $33.73-405$ & \\
\hline & & Mollusks & Range & $1.45-5.77$ & $0.36-35.36$ & na & $19.06-79.54$ & $0.00002-0.00082$ & na & na & $0.026-1.576$ & $21.26-140$ & \\
\hline
\end{tabular}




\begin{tabular}{|c|c|c|c|c|c|c|c|c|c|c|c|c|c|}
\hline \multirow[t]{10}{*}{ Qinhuangdao } & Jul. to Aug., 2002 & Rapana venosa & Mean & na & 4.29 & na & 14.08 & 0.0417 & na & 0.38 & 0.13 & 33.21 & $\begin{array}{l}\text { Liang et al. } \\
(2003,2004)\end{array}$ \\
\hline & Oct. to Nov., 2005 & Argopecten irradians & Mean & 0.18 & na & na & 3.07 & 0.007 & na & na & 0.17 & 73.82 & Wang et al. (2007) \\
\hline & \multirow[t]{7}{*}{ Apr. to May, 2010} & Clupanodon thrissa & Mean & 2.06 & $5.92^{\mathrm{e}}$ & $12.5^{\mathrm{e}}$ & 1.47 & na & na & $14.2^{\mathrm{e}}$ & $10.0^{\mathrm{e}}$ & 12.6 & $\begin{array}{l}\text { Zhang and Wang } \\
\text { (2012) }\end{array}$ \\
\hline & & Cynoglossus joyneri & Mean & 12.1 & $5.30^{\mathrm{e}}$ & $30.2^{\mathrm{e}}$ & 0.38 & na & na & $37.2^{\mathrm{e}}$ & $72.5^{\mathrm{e}}$ & 5.40 & \\
\hline & & Glossogobius giuris & Mean & 1.00 & $12.7^{\mathrm{e}}$ & $16.2^{\mathrm{e}}$ & 0.57 & na & na & $28.2^{\mathrm{e}}$ & $12.4^{\mathrm{e}}$ & 12.2 & \\
\hline & & Hemirhanphus sajori & Mean & 1.28 & $5.05^{\mathrm{e}}$ & $17.0^{\mathrm{e}}$ & 0.37 & na & na & $15.6^{\mathrm{e}}$ & $4.58^{\mathrm{e}}$ & 19.8 & \\
\hline & & Lateolabrax japonicus & Mean & 2.19 & $3.18^{\mathrm{e}}$ & $12.1^{\mathrm{e}}$ & 0.38 & na & na & $9.95^{\mathrm{e}}$ & $3.65^{\mathrm{e}}$ & 10.9 & \\
\hline & & Platycephalus indicus & Mean & 1.72 & $2.42^{\mathrm{e}}$ & $12.2^{\mathrm{e}}$ & 0.35 & na & na & $13.5^{\mathrm{e}}$ & $2.72^{\mathrm{e}}$ & 5.48 & \\
\hline & & Scorpaena neglecta & Mean & 1.15 & $15.0^{\mathrm{e}}$ & $16.7^{\mathrm{e}}$ & 0.36 & na & na & $30.8^{\mathrm{e}}$ & $8.85^{\mathrm{e}}$ & 6.88 & \\
\hline & Nov. and Dec., 2010 & $\begin{array}{l}\text { Ruditapes } \\
\text { philippinarum }\end{array}$ & Range & $0.62-0.94$ & $0.09-0.11$ & $0.24-0.33$ & $2.86-5.43$ & $0.02-0.03$ & na & $1.18-1.75$ & $0.09-0.10$ & $17.47-24.04$ & Yang et al. (2013) \\
\hline Tanggu & Jul. to Aug., 2002 & Rapana venosa & Mean & na & 3.32 & na & 41.57 & 0.0378 & na & 0.09 & 0.12 & 48.61 & $\begin{array}{l}\text { Liang et al., } 2003 \\
\text { (2004) }\end{array}$ \\
\hline Yangkou & Jul. to Aug., 2002 & Rapana venosa & Mean & na & 0.15 & na & 9.98 & 0.0591 & na & 0.66 & 0.75 & 8.65 & $\begin{array}{l}\text { Liang et al. } \\
(2003,2004)\end{array}$ \\
\hline Laizhou Bay & Oct. to Nov., 2005 & Argopecten irradians & Mean & 0.34 & na & na & 3.66 & 0.024 & na & na & 0.13 & 51.53 & Wang et al. (2007) \\
\hline \multirow[t]{2}{*}{ Penglai } & Jul. to Aug., 2002 & Rapana venosa & Mean & na & 24.71 & na & 48.74 & 0.0979 & na & 0.47 & 0.23 & 73.75 & $\begin{array}{l}\text { Liang et al. } \\
(2003,2004)\end{array}$ \\
\hline & Oct. to Nov., 2005 & Argopecten irradians & Mean & 0.42 & na & na & 1.92 & 0.015 & na & na & 0.07 & 42.51 & Wang et al. (2007) \\
\hline Dalian Bay & 1987-1990 & Mollusks & Mean & 1.72 & 7.30 & na & 2.65 & 0.13 & na & na & 2.70 & 34.50 & Ma et al. (1995) \\
\hline \multirow[t]{3}{*}{ Dayao Bay } & \multirow[t]{3}{*}{$1987-1990$} & Fish & Mean & 0.24 & 0.05 & na & 0.24 & 0.06 & na & na & 0.03 & 7.5 & Ma et al. (1995) \\
\hline & & Crustacea & Mean & na & 0.08 & na & 10.55 & 0.16 & na & na & 0.72 & 20.35 & \\
\hline & & Mollusks & Mean & 2.23 & 0.70 & 0.08 & 0.30 & 0.05 & na & na & 0.89 & 27.7 & \\
\hline Jinzhouwan Bay & 1987-1990 & Mollusks & Mean & 0.21 & 0.48 & na & 1.6 & 0.02 & na & na & 7.93 & 7.93 & Ma et al. (1995) \\
\hline & & Mollusks & & na & 2 & na & 10 & 0.5 & na & na & na & 100 & WHO (1982) \\
\hline \multirow[t]{2}{*}{ Hygienic standard } & & Fish & & $<0.1$ & $<0.1$ & na & na & na & $<1.0$ & na & $<0.5$ & na & MHPR (2005) \\
\hline & & $\begin{array}{l}\text { Other marine } \\
\text { organisms }\end{array}$ & & $<0.5$ & na & na & na & na & $<0.5$ & na & na & na & \\
\hline Grade $\mathrm{I}^{\mathrm{g}}$ & & Shellfish & & $\leq 1.0$ & $\leq 0.2$ & $\leq 0.5$ & $\leq 10$ & $\leq 0.05$ & na & na & $\leq 0.1$ & $\leq 20$ & SEPA (2001) \\
\hline Grade II ${ }^{\mathrm{h}}$ & & Shellfish & & $\leq 5.0$ & $\leq 2.0$ & $\leq 2.0$ & $\leq 25$ & $\leq 0.1$ & na & na & $\leq 2.0$ & $\leq 50$ & SEPA (2001) \\
\hline Grade III ${ }^{\mathrm{i}}$ & & Shellfish & & $\leq 8.0$ & $\leq 5.0$ & $\leq 6.0$ & $\leq 50^{\mathrm{j}}$ & $\leq 0.3$ & na & na & $\leq 6.0$ & $\leq 100^{k}$ & SEPA (2001) \\
\hline $\begin{array}{l}\text { a } \text { Total mercury. } \\
\text { b } \text { Methylmercury. } \\
\text { c na: not available. } \\
\text { d GM } \pm \text { SD: geome } \\
\text { e } \text { ng/g wet weight. } \\
\text { f MPL: Maximum p } \\
\text { g Grade I: National } \\
\text { h } \text { Grade II: National } \\
\text { i Grade III: Nationa } \\
\text { j } 100 \text { for ostracean. } \\
\text { k } 500 \text { for ostracean }\end{array}$ & $\begin{array}{l} \pm \text { standard deviation. } \\
\text { le levels. } \\
\text { lof China for Marine Bi } \\
\text { d of China for Marine B } \\
\text { d of China for Marine B }\end{array}$ & $\begin{array}{l}\text { Biological Quality GB } 18 \\
\text { Biological Quality GB } 18 \\
\text { Biological Quality GB } 18\end{array}$ & $\begin{array}{l}421-200 \\
3421-200 \\
3421-200\end{array}$ & $\begin{array}{l}\text { de I. } \\
\text { ade II. } \\
\text { ade III. }\end{array}$ & & & & & & & & & \\
\hline
\end{tabular}


Bay and the northern South China Sea (e.g. Gao et al., 2008, 2010). As shown in Fig. 3, for the Bohai Bay, on average, $\mathrm{Cr}, \mathrm{Cu}, \mathrm{Ni}$ and $\mathrm{Zn}$ in riverine, nearshore and intertidal surface sediments, and $\mathrm{Pb}$ in intertidal surface sediments were all dominated by residual fraction; $\mathrm{Cd}$ in riverine, nearshore and intertidal surface sediments was dominated by acid-soluble fraction; and $\mathrm{Pb}$ in riverine and nearshore surface sediments was dominated by reducible fraction (Gao and Chen, 2012; Gao and Li, 2012). Different existing forms of trace metals in sediment represent different sources. The residual fraction represents natural sources and the acid-soluble fraction represents mainly anthropogenic sources (Chen and Liu, 1992). The difference in the distribution of trace metals in different geochemical fractions is primarily caused by their chemical properties as well as by the physicochemical conditions of the environment and the impact of human activities.

The metals in acid-soluble fraction are considered to be the weakest bonded metals in sediments which may equilibrate with the aqueous phase and thus become more mobile and easily bioavailable (Pardo et al., 1990). The higher the proportion of metals in this fraction, the more mobile they are, and the higher the risk they could pose to the environment. So, among $\mathrm{Cd}, \mathrm{Cr}, \mathrm{Cu}, \mathrm{Ni}, \mathrm{Pb}$ and $\mathrm{Zn}, \mathrm{Cd}$ was the most mobile one with the highest environmental risk and $\mathrm{Cr}$ was the least mobile one with the lowest environmental risk in surface sediments of the coastal Bohai Bay. The percentages of acid-soluble $\mathrm{Cr} / \mathrm{Cu} / \mathrm{Ni} / \mathrm{Pb}$ in riverine, nearshore and intertidal sediments were comparable; but $\mathrm{Zn}$ in riverine sediment was more mobile than in nearshore and intertidal sediments (Fig. 3). The metals in the residual fraction were generally an indication of lithogenic input, while those in non-residual fractions could mainly be explained by anthropogenic inputs. Indicated by the significant correlations between $\mathrm{Cd}, \mathrm{Cr}, \mathrm{Cu}, \mathrm{Ni}, \mathrm{Pb}$ and $\mathrm{Zn}$ in the non-residual fraction and their corresponding $\mathrm{EF}$ values, anthropogenic inputs were probably the major contributor to their enrichment in the riverine and nearshore surface sediments of the coastal Bohai Bay; however, for $\mathrm{Cu}, \mathrm{Ni}$ and $\mathrm{Pb}$, the contribution of lithogenic input was as important as that of anthropogenic inputs (Gao and Chen, 2012).

A five-step sequential extraction procedure modified based on the work of Tessier et al. (1979) was applied to investigate the fractionation of $\mathrm{Cd}, \mathrm{Cu}$ and $\mathrm{Pb}$ in sediments of the Jinzhou Bay and the results indicated that $\mathrm{Cd}$ was dominated by the exchangeable fraction, $\mathrm{Cu}$ was dominated by the residual fraction and $\mathrm{Pb}$ was dominated by the fraction bound to $\mathrm{Fe} / \mathrm{Mn}$ oxides (Wang et al., 2010b). In the sequential extraction procedure of Tessier et al. (1979), trace metals in exchangeable and carbonate-bound fractions are considered to be with high potential environmental risks. The sum of exchangeable and carbonate-bound fractions accounted for up to $79 \%$ of $\mathrm{Cd}$ in total concentration, and it was $26 \%$ for $\mathrm{Cu}$ and $17 \%$ for $\mathrm{Pb}$ in sediments of the Jinzhou Bay (Wang et al., 2010b). Considering the high total concentrations of $\mathrm{Cd}$, $\mathrm{Cu}$ or $\mathrm{Pb}$ in sediments of the Jinzhou Bay, which was up to $64 \mu \mathrm{g} \mathrm{g}^{-1}$ for $\mathrm{Cd}, 417 \mu \mathrm{g} \mathrm{g}^{-1}$ for $\mathrm{Cu}$ and $752 \mu \mathrm{g} \mathrm{g}^{-1}$ for $\mathrm{Pb}$ (Table 2), they were serious threats to the environment and ecosystem of this bay.

As one of the major chemical constituents of aquatic sediments, acid-volatile sulfide (AVS) plays an important role in controlling the activities and availability of divalent metal cations, which are mainly $\mathrm{Cd}^{2+}, \mathrm{Cu}^{2+}, \mathrm{Pb}^{2+}, \mathrm{Ni}^{2+}$ and $\mathrm{Zn}^{2+}$, in the interstitial waters of sediments. AVS is operationally defined as the reactive sulfide fraction in sediment that can be volatilized with cold hydrochloric acid (usually $1 \mathrm{M}$ or $6 \mathrm{M}$ ). The sulfide-bound metals that were extracted during this process at the same time are called "simultaneously extracted metals" (SEM). Gao et al. (2013) and Zhuang and Gao (2013) used the relationships between the molar concentrations of AVS and SEM to assess the quality of the surface sediments from the Laizhou Bay and the surrounding rivers discharging into its southwestern coast. The results indicated that SEM was present at lower concentrations than AVS for all samples except few riverine ones, which meant there was no indication of associated adverse effects of the five constituents of $\mathrm{SEM}$, namely $\mathrm{Cd}, \mathrm{Cu}, \mathrm{Pb}, \mathrm{Ni}$ and $\mathrm{Zn}$, on aquatic life.

\subsection{Trace metals in organisms}

Marine organisms can accumulate trace metals from seawaters, suspended particles, sediments, and food chains. Bioaccumulation of metals varies strongly among different areas and species. Meanwhile, it also follows certain rules. Generally, organisms accumulate high amounts of metals when they are in the environment that has trace metals (of bioavailability) with high concentrations. So, the concentrations of metals in organisms can reflect the extent of environmental pollution and some species are good bioindicators of the pollution status of certain metals.

The concentrations of $\mathrm{As}, \mathrm{Cd}, \mathrm{Hg}, \mathrm{Cu}$ and $\mathrm{Pb}$ in some organisms of the Bohai Sea exceeded relevant standards. Huludao is a hot site in the coastal zone of the Bohai Sea that showed metal pollution in marine organisms (Fig. 3C). Some species like Rapana venosa and Ruditapes philippinarum were appropriate bioindicators of metal pollution in organisms of the Bohai Sea (Liang et al., 2004; Wang et al., 2005a).

\subsubsection{The situation of different metals}

The background situation of metals in organisms should be mentioned for a good understanding of the pollution situation of organisms by trace metals in the Bohai Sea. Liu et al. (1983) investigated $\mathrm{Cd}, \mathrm{Cu}, \mathrm{Pb}$ and $\mathrm{Zn}$ in 35 species of fish, crustacean and mollusks collected from the Bohai Bay in 1981 and found that the concentrations of these trace metals were not high compared with other areas in the world (Liu et al., 1983). This is the earliest report on trace metals in marine organisms of the Bohai Sea and related values are listed in Table 3.

The situation of $\mathrm{As}, \mathrm{Cd}, \mathrm{Cr}, \mathrm{Cu}, \mathrm{Hg}, \mathrm{Ni}, \mathrm{Pb}$ and $\mathrm{Zn}$ in marine organisms of the Bohai Sea in recent years is summarized as follows. National Standard of China for Marine Biological Quality (MBQ) GB 18421-2001 (SEPA, 2002) is often used to evaluate the pollution situation of trace metals in shellfish in China. This standard divides the concentration of trace metals in shellfish into three levels (Table 3). The Grade I level is applicable for marine fishing, aquaculture and natural reserve; Grade II is applicable for water supply of general industry and scenic spot; and Grade III is applicable for performance of harbor and industry development. Liu et al. (2007) studied As in 10 species of benthic mussels from 17 coastal sites of the Bohai Sea and found that the concentrations of As from all sites except one in the coastal Laizhou Bay were within the range of MBQ Grade I. Therefore, generally As was not an element with high ecological risks in the Bohai Sea and this was also in accordance with the report of Wang et al. (2007).

The concentrations of $\mathrm{Cd}$ in some of the nine species of mollusks collected from eight coastal sites of the Bohai Sea during 2002 and 2003 exceeded the maximum permissible level (MPL) for $\mathrm{Cd}$ in food product recommended by the World Health Organization (WHO) in 1982 (Table 3; Wang et al., 2005a). In some gastropods and oysters collected during July to August 2002 along the coastline of the Bohai Sea, the concentration of Cd also exceeded the MPL (Liang et al., 2004). Similarly, its concentration in different mussel species from the coastal Bohai Sea commonly exceeded the upper limit of MBQ Grade II, which is equal to its MPL value (Liu et al., 2007).

As for $\mathrm{Cr}$ and $\mathrm{Ni}$, related reports are relatively few (Table 3 ). The report of Wang et al. (2005a) demonstrated that the average concentrations of $\mathrm{Cr}$ in different species of mollusks from the coastal Bohai Sea fluctuated around the upper limit of MBQ Class I; Ni is not an element used to judge the biological quality in the National Standard of China GB 18421-2001 and its concentrations in mollusks of the Bohai Sea varied within a range comparable to that of $\mathrm{Cr}$ (Liang et al., 2004; Wang et al., 2005a). The same report indicated that the concentrations of $\mathrm{Cu}$ in some species of mollusks exceeded its MPL value (Wang et al., 2005a). The concentrations of $\mathrm{Cu}$ in Argopecten irradians (bivalve) and Chlamys farreri (bivalve) collected from the mariculture areas of Qinhuangdao and the Laizhou Bay did not exceed the guideline of MBQ Grade I (Wang et al., 2007). 
The concentrations of $\mathrm{Hg}$ in the tissue of selected mollusks in the Bohai Bay during 2002 and 2003 were relatively low and less than its MPL $\left(0.5 \mu \mathrm{g} \mathrm{g}^{-1}\right)$ (Wang et al., 2005a, 2005b). Consistent with this, the investigation of trace metals in A. irradians and C. farreri collected from the mariculture areas of Qinhuangdao and the Laizhou Bay in 2005 indicated that the concentrations of $\mathrm{Hg}$ all fell in the range of MBQ Grade I $\left(0.05 \mu \mathrm{g} \mathrm{g}^{-1}\right)$ (Wang et al., 2007). However, the study of Liu et al. (2007) showed that the concentrations of $\mathrm{Hg}$ in benthic mussels from some coastal sites in the Liaodong Bay and the Laizhou Bay exceeded the guideline for MBQ Class II, but were still within the range of MPL. In general, mollusks in the Bohai Sea are polluted to some extent.

$\mathrm{Hg}$ in organisms exists in many forms among which methylmercury (MeHg) is the most toxic. Seafood is considered to be the main source of MeHg in the human diet (Jiang et al., 2006). Though in China, aquatic foods contribute only $9.7 \%$ of $\mathrm{Hg}$ intake, which is less than many other countries, their consumption is still a major intake source for people around the Bohai Sea (Jiang et al., 2006). So, the determination of $\mathrm{MeHg}$ as well as total mercury $(\mathrm{THg}$ ) is of great importance. The report of Liang et al. (2003) demonstrated that the mercury contamination commonly existed in gastropod and bivalve species collected from eight coastal sites along the Bohai Sea, with $\mathrm{MeHg}$ and $\mathrm{THg}$ concentration in the range of $0.005-0.168$ and $0.007-0.453 \mu \mathrm{g} \mathrm{g}^{-1}$, respectively, of which the maximum value of $\mathrm{MeHg}$ did not exceed the hygienic standard for fresh and frozen marine products of animal origin (GB2733-2005) (MHPR, 2005) but the maximum value of THg exceeded the range of MBQ Grade III. Wang et al. (2005b) got a similar result as Liang et al. (2003). Crucian carp is one of the most consumed aquatic species in China (Luo et al., 2012). The average concentrations of $\mathrm{Hg}$ and $\mathrm{MeHg}$ in carp collected along the North Bohai Sea were less than the maximum permissible level (WHO, 1982) for $\mathrm{Hg}$ and the hygienic standard (MHPR, 2005) for MeHg, respectively (Table 3; Luo et al., 2012). Nevertheless, carp in that area still had a potential risk to human health considering the high ratio of MeHg to THg (Luo et al., 2012). Besides, predators that eat crucian carp, like birds, would be also at risk to some extent. Crabs collected along the North Bohai Sea had a worse situation than crucian carp in that area, with the average concentrations of $\mathrm{THg}$ and $\mathrm{MeHg}$ exceeding the maximum permissible level (WHO, 1982) for Hg and the hygienic standard (MHPR, 2005) for MeHg, respectively (Table 3; Luo et al., 2012). However, the risk of crab to human health is possibly small considering its low ratio of $\mathrm{MeHg}$ to $\mathrm{Hg}$ and low cosumption compared with that of carp (Luo et al., 2012).

$\mathrm{Pb}$ concentration in mollusks of the Bohai Sea was very low during 2002 and 2003 according to the study of Wang et al. (2005a). However, because $\mathrm{Pb}$ and its salts were capable of causing hematosis and damaging the nervous system and kidneys of the human body, even low concentrations of $\mathrm{Pb}$ in food could not be ignored (Chuang et al., 2004; Wang et al., 2005a). The concentrations of $\mathrm{Pb}$ in A. irradians and C. farreri collected from mariculture areas of Qinhuangdao and the Laizhou Bay in 2005 did not exceed the range of MBQ Grade I (Wang et al., 2007), while in the study of Liu et al. (2007), the concentrations of $\mathrm{Pb}$ in some samples of benthic mussels from the Liaodong Bay and the Laizhou Bay exceeded the standard. The concentrations of $\mathrm{Zn}$ in some mollusks collected along the coastline of the Bohai Sea during 2002 and 2003 exceeded the MPL, indicating that Zn may have potential ecological risk to the environment of that area (Liang et al., 2004; Wang et al., 2005a).

He (1996) studied $\mathrm{Cd}, \mathrm{Cr}, \mathrm{Cu}, \mathrm{Pb}$ and $\mathrm{Zn}$ in the main economic mollusks collected from the coastal region of the Bohai Sea and the Yellow Sea in 1990 and found that only the average concentration of $\mathrm{Cu}$ did not exceed the MBQ Grade I. This showed that the economic mollusks were polluted to some extent. Hazard quotients of $\mathrm{As}, \mathrm{Cd}, \mathrm{Cr}$, $\mathrm{Cu}, \mathrm{Ni}, \mathrm{Pb}$ and $\mathrm{Zn}$ in fish species and bivavel $R$. philippinarum collected from Qinhuangdao were all less than 1, manifesting there was no obvious health risk from the intake of these marine organisms (Yang et al., 2013; Zhang and Wang, 2012). A survey made a historical comparison of concentrations in marine organisms and demonstrated that the concentrations of $\mathrm{As}, \mathrm{Cd}, \mathrm{Hg}$ and $\mathrm{Pb}$ in most benthic mussel samples collected from the Bohai Sea showed a decreasing trend or remained steady (Liu et al., 2011c).

\subsubsection{The situation of different areas}

The Jinzhou Bay and Huludao are widely known for their suffering from metal pollution. Among the Dayao Bay, Dalian Bay, Jinzhouwan Bay and Jinzhou Bay (Fig. 1), the four seriously anthropogenically influenced marine areas along the coast of Liaoning Province, the Jinzhou Bay had the highest concentrations of $\mathrm{Hg}$ and $\mathrm{Cu}$ in marine organisms (Ma et al., 1995). $R$. venosa is a species of large predatory sea snail, a marine gastropod mollusk or whelk, in the family Muricidae, the rock shells. This species is native to the marine and estuarine waters of the Bohai Sea. $R$. venosa from Huludao exhibited the highest values of $\mathrm{Cd}\left(30.61 \mathrm{mg} \mathrm{kg}^{-1}\right), \mathrm{Cu}\left(172.25 \mathrm{mg} \mathrm{kg}^{-1}\right)$ and $\mathrm{Zn}\left(705 \mathrm{mg} \mathrm{kg}^{-1}\right)$ among the sampling sites surrounding the Bohai Sea. While those collected from Penglai took the second place (Liang et al., 2004). The rank of $\mathrm{Hg}$ concentrations in mollusks among these sites was similar to that of Cd, Cu and Zn (Liang et al., 2003). Wang et al. (2005a) also reported that $\mathrm{Cd}$ in mollusks from Huludao had the highest contents compared with the other sampling sites surrounding the Bohai Sea.

The Laizhou Bay is also an area presenting high concentrations of trace metals in marine organisms. Liu et al. (2007) pointed out that $\mathrm{As}, \mathrm{Cd}, \mathrm{Hg}$ and $\mathrm{Pb}$ in benthic mussels from the area of the southwestern Laizhou Bay displayed higher average concentrations compared with other areas of the Bohai Sea (Liu et al., 2007). The reason for this might be that the area is close to the mouth of Xiaoqinghe River which discharges about $30 \%$ of the whole pollutants that run into the Laizhou Bay (Liu et al., 2004).

The Bohai Sea is one of the most polluted areas in terms of metal pollution in organisms compared with other coastal areas in China. Wang et al. (2005a) compared the trace metal contents in soft tissues of Mytilus edulis (bivalve) in their study with those from other sites along the Chinese coastline and found that Penglai and Huludao were the most seriously polluted cities by trace metals. Penglai's pollution came from the local paper mills and the indigenous method of smelting gold. The largest zinc industry in Asia is located in Huludao and it is the major pollution source for the city. Another publication reported that among the seven mariculture areas in the northern China seas including the Dalian Bay, Qinhuangdao, the Laizhou Bay, Yantai, Weihai, the Jiaozhou Bay and Jiaonan, the concentration of $\mathrm{Hg}\left(0.024 \mu \mathrm{g} \mathrm{g}^{-1}\right)$ in A. irradians of the Laizhou Bay was the highest and the concentration of As $\left(0.34 \mu \mathrm{g} \mathrm{g}^{-1}\right)$ in this bivalve species from the Laizhou Bay ranked the second highest among these areas (Wang et al., 2007). Qinhuangdao was the only site in the Bohai Bay that was studied by Zhang and Wang (2012). Cd in fish species from Qinhuangdao had higher concentrations than that from Huilai, the Pearl River Estuary, Zhejiang and Haikou (Zhang and Wang, 2012). Yang et al. (2013) also showed that along the coast of China, Qinhuangdao was one of the hotspots for the trace element contamination in bivalve $R$. philippinarum.

\subsubsection{The situation of different species}

Different organism species in the Bohai Sea have different abilities in accumulating trace metals. Ma et al. (1995) compared the concentrations of trace metals in organisms of the Jinzhou Bay and other bays of Liaoning Province and found that metal concentration in the organisms had a relationship with not only the marine environment but also species, years and features. Two recent studies explained part of these phenomena from their species and characteristics. There are dominantly three species of clams (White, Liangdao Red and Zebra) along the coast of the Bohai Sea (Liu et al., 2011d, 2011e). When the adductor muscle was used as the target organ, White clams could be a preferable bioindicator of the pollution monitoring for dissolved mercury compared with the other two clam species, i.e. Liangdao Red 
and Zebra (Liu et al., 2011d); while, when digestive gland tissue was used as the target organ, Liangdao Red clams exhibited more sensitive disturbances to the mercury exposure (Liu et al., 2011e).

Significant differences in accumulating different metals were found among different species collected from the sea area near Huludao (Yue and Shi, 2001). Fish, crustacean and mollusks had a low ability in accumulating $\mathrm{Hg}$ and $\mathrm{Pb}$ but a high ability in accumulating $\mathrm{As}, \mathrm{Cu}$, $\mathrm{Cd}$ and $\mathrm{Zn}$. The latter two groups of marine organisms accumulated trace metals with higher concentrations than the former one (Ma et al., 1995; Yue and Shi, 2001). Species that have special ability in accumulating certain metals can act as a biomonitor. Wang et al. (2005a) studied the accumulation of trace metals of nine kinds of mollusks ( $R$. venosa, Neverita didyma, Scapharca subcrenata, M. edulis, Amusium, Crassostrea talienwhanensis, Meretix meretrix, R. philippinarum, and Mactra veneriformis) in the Bohai Sea. Gastropods ( $R$. venosa and $N$. didyma) were loaded with higher As and $\mathrm{Hg}$ than bivalves, $R$. venosa, Amusium, S. subcrenata, and M. veneriformis presented higher Cd levels than others, and M. meretrix and $R$. philippinarum had larger enrichment of Ni than others manifesting the fact that they can act as bioindicators of corresponding metals (Wang et al., 2005a). The study of Liang et al. (2004) also demonstrated that $R$. venosa and $R$. philippinarum were hopeful bioindicators of monitoring $\mathrm{Cd}$ and $\mathrm{Ni}$ pollution, similar to the report of Wang et al. (2005a).

Few studies focused on trace metals in marine fish and crabs from the Bohai Sea. Fish and crabs are the major seafood for humans. Knowing the situation of trace metals in them is of great importance. Zhang and Wang (2012) conducted a large scale investigation of twelve trace element levels in twenty-nine marine fish species collected from Chinese coastal waters. Qinhuangdao was the only studied site located in the Bohai Sea. Cynoglossus joyneri showed the highest concentrations of $\mathrm{As}, \mathrm{Cr}, \mathrm{Ni}$ and $\mathrm{Pb}$ and Hemirhamphus sajori had the highest concentration of $\mathrm{Zn}$ compared with other different fish species collected from Qinhuangdao (Zhang and Wang, 2012). Luo et al. (2013) studied Cd and $\mathrm{Zn}$ in carps and crabs from the upstream and downstream regions of coastal watersheds along the Northern Bohai Sea. Concentration of $\mathrm{Cd}$ in these two species was obviously low compared with that of other species listed in Table 3. While this was not the situation for $\mathrm{Zn}$ in carps and crabs (Table 3).

\subsection{The relations between trace metals in the seawaters, sediments and organisms}

As shown in Fig. 2, the pollution status was the worst in the western Bohai Bay and the northern Liaodong Bay, especially in the coast of Huludao. By comparing with SWQ MSQ and MBQ the degree of sediment pollution by trace metals was much greater than that of seawaters and marine biological pollution (Tables 1, 2 and 3; Fig. 2). The Bohai Sea should be seen as a whole system to get a good understanding of the information of trace metals for there is a close relationship among the concentrations of trace metals in the seawaters, sediments and organisms. Based on the summarized data of trace metals in the waters, sediments and organisms of the Bohai Sea, we found that trace metals in these three media all had relatively higher concentrations in the Jinzhou Bay and Huludao compared with other areas in the Bohai Sea (Tables 1, 2 and 3). This obviously explained that trace metals in these three media influenced mutually.

Unfortunately, until now not much literature has ever linked trace metals in these three media together. Ma et al. (1995) compared the pollution status of trace metals in the sea waters, sediments and organisms in bays of Liaoning Province based on the content in these three media, which may not be correct, and concluded that considering the concentrations of $\mathrm{Cu}$ and $\mathrm{Zn}$ sediments were most polluted, followed by organisms, and seawaters were the least polluted. The comparison of sediments, seawaters and organisms is beneficial to the conduction of research on relations among them which then can help select the more representative medium and simplify the sampling.
There is a close connection between trace metals in waters and sediments. Zhang et al. (2010a) reported that in the intertidal zone of the Yongdingxinhe River mouth in the western Bohai Bay, the order of the average trace metal contents in sediments was the same as that in seawaters, $\mathrm{Zn}>\mathrm{Cu}>\mathrm{Pb}>\mathrm{Hg}>\mathrm{Cd}$, which indicated that trace metals in sediments and seawaters were in an equilibrium state. Meng et al. (2008) also demonstrated that $\mathrm{Pb}$ and $\mathrm{Zn}$ were found as the main trace metal pollutants in both waters and surface sediments of the Bohai Bay. So, if other conditions such as hydraulics, winds and salinity are similar, it is likely to predict the environmental situation of trace metals in one medium based on another medium.

Trace metals in seawaters may affect marine organisms directly. Based on this, some researchers evaluated the water condition of the Bohai Sea or determined trace metal biomonitors for the water condition. Zhang et al. (2010b, 2010c) used a widely maricultured bivalve species, $C$. farreri, in China to study its physiological change under the trace metal concentration levels equivalent to those in the seawaters of the Bohai Bay and determined the potential harmful elements. The results indicated that among $\mathrm{Cd}, \mathrm{Cu}, \mathrm{Hg}, \mathrm{Pb}$ and $\mathrm{Zn}$, the concentrations of $\mathrm{Cd}$ and $\mathrm{Pb}$ might have reached a level with potential risks to organisms.

Besides, the dietary exposure is another important way for trace metals to affect marine organisms. Organisms of low trophic level like phytoplankton can absorb certain trace metals in waters. Organisms of higher trophic level can accumulate trace metals by eating organisms of lower trophic level. When humans eat those organisms which accumulate high concentrations of trace metals, they may get pathological lesions. For example, minamata is caused by eating fish that has $\mathrm{MeHg}$ of high concentrations. In the study of Luo et al. (2013), the relationships among $\mathrm{Cd}$ and $\mathrm{Zn}$ concentrations in waters, sediments and biota were studied. Results showed that $\mathrm{Cd}$ and $\mathrm{Zn}$ in crabs were primarily derived from sediment exposure. This was due to the fact that crabs are bottom dwellers and they take up $\mathrm{Cd}$ and $\mathrm{Zn}$ indirectly by eating sediment-dwelling invertebrates (Luo et al., 2013).

\section{Concluding remarks and perspectives}

The Bohai Sea has been considered as one of the most polluted marine areas in China. Metals from various sources have put much pressure on its ecosystems. The structure of the phytoplankton community has changed, causing the decline of fish species in the Bohai Sea. Besides, fish and other marine products are no longer as safe as before because they accumulate trace metals which may do harm to human health when they reach a certain concentration. River discharge, sediments release, industrial waste drainage and atmospheric sedimentation are the major sources of the pollutants in the Bohai Sea. The whole situation of the Bohai Sea does not seem to be that serious in terms of trace metals. However, it is particularly worrisome that relatively high concentrations of trace metals occur in estuaries and bays in the Bohai Sea. Based on the rough historical change summarized from Tables 1, 2 and 3, we found that trace metals in the Bohai Sea did not increase much and even declined to some extent in recent years. This demonstrated that the 'Bohai Blue Sea Action Plan' and other pollution control programs may have certain effects. So we suggest further implementing these pollution control programs.

There is a lack of systematic cooperation in the studies on trace metals in the Bohai Sea which is the same situation as other sea areas in China. Too much attention has been paid to a few local/regional coastal areas and little attention has been paid to the rest of the Bohai Sea. Systematic cooperation in studies is in urgent need for the effective protection of the Bohai Sea. There are many methods applicable for the determination of benchmarks of heavy metals in marine environment, their environmental/ecological risks and so on, which makes it difficult to compare the results of different researchers' studies and draw satisfying conclusions. So a system of targeted standard methods should be established to handle these issues. Just knowing the pollution status 
is far from enough. The knowledge of the sources, sinks and fluxes of trace metals can make us understand more clearly the environmental status of the Bohai Sea. More investigations of trace metals for their sink and source modeling should be conducted. The knowledge of the speciation and fractionation of trace metals in the Bohai Sea and the influence of submarine groundwater discharges on the biogeochemistry of trace metals is almost blank and related work needs to be carried out urgently.

\section{Acknowledgments}

This study was co-supported by the National Natural Science Foundation of China (41376083), the Department of Science and Technology of Shandong Province (2012GHY11535), the CAS/SAFEA International Partnership Program for Creative Research Teams (Representative Environmental Processes and Resources Effects in Coastal Zone) and the Taiwan's aim for the Top University Program.

\section{References}

Burton Jr GA. Sediment quality criteria in use around the world. Limnology 2002;3:65-76 Carr RS, Long ER, Windom HL, Chapman DC, Thursby G, Sloane GM, et al. Sediment quality assessment studies of Tampa Bay, Florida. Environ Toxicol Chem 1996;15:1218-31.

Chen JS, Liu YJ. Study on water environment of heavy metals in China. China Environmental Science Press; 1992. p. 168-70. [In Chinese].

Chen C, Liu H, Beardsley RC. An unstructured grid, finite-volume, three-dimensional, primitive equations ocean model: application to coastal ocean and estuaries. J Atmos Oceanic Tech 2003;20:159-86.

Chen JL, Liu WX, Liu SZ, Lin XM, Tao S. An evaluation on heavy metal contamination in the surface sediments in Bohai Sea. Mar Sci 2005;28:16-21. [In Chinese with English abstract].

Chuang HY, Tsai SY, Chao KY, Lian CY, Yang CY, Ho CK, et al. The influence of milk intake on the lead toxicity to the sensory nervous system in lead workers. Neurotoxicology 2004:25:941-9.

Cui Y, Song Y, Yang Q, Yu H. A preliminary study on the relationship between phytoplankton and physicochemical factors in Bohai Sea. Mar Environ Sci 1992;11: 56-9. [In Chinese with English abstract].

Cui Y, Chen BJ, Song YL. Heavy metals content in sea water and marine organisms at Jiaozhou Bay. Chin J Appl Ecol 1997;6:650-4. [In Chinese with English abstract].

Dai MX, Peng ST, Xu J, Liu CG, Jin XL, Zhan SF. Decennary variations of dissolved heavy metals in seawater of Bohai Bay, North China. Bull Environ Contam Toxicol 2009;83:907-12.

Diao HX. The environmental assessment of temperature phosphate and silicate on phytoplankton in Bohai Sea water. Trans Oceanol Limnol 1986;2:35-40. [In Chinese with English abstract].

Duan LQ Song JM, Li XG, Yuan HM. The behaviors and sources of dissolved arsenic and antimony in Bohai Bay. Cont Shelf Res 2010;30:1522-34.

Editorial Board for Marine Atlas, editor. Marine atlas of Bohai Sea, Yellow Sea and East China Sea. Beijing, China: Ocean Press; 1991. [In Chinese].

Fan WH, Zhang B, Chen JS, Zhang R, Deng BS. Pollution and potential biological toxicity assessment using heavy metals from surface sediments of Jinzhou Bay. Acta Sci Circumst 2006;6:1000-5. [In Chinese with English abstract]

Fan WH, Zhang B, Zhang R, Deng BS. Speciation characteristics and potential ecological risk of heavy metals in surface sediments of Jinzhou Bay. Mar Environ Sci 2008;27(1):54-8. [In Chinese with English abstract].

Fei Z. The study of primary production in the Bohai Sea: chlorophyll a, primary productivity and potential fisheries resources. Mar Fish Res 1991;12:55-69. [In Chinese with English abstract].

Feng MH, Long JP, Yu L, Li JJ. Ecological risk evaluation of heavy metals of marine sediment in Liaodong Bays shallow waters. Mar Sci 2003;27:52-6. [In Chinese with English abstract].

Feng HA, Jiang HY, Gao WS, Weinstein MP, Zhang QF, Zhang WG, et al. Metal contamination in sediments of the western Bohai Bay and adjacent estuaries, China. J Environ Manage 2011;92:1185-97.

Gao XL, Chen CTA. Heavy metal pollution status in surface sediments of the coastal Bohai Bay. Water Res 2012;46:1901-11.

Gao XL, Li PM. Concentration and fractionation of trace metals in surface sediments of intertidal Bohai Bay, China. Mar Pollut Bull 2012;64:1529-36.

Gao XL, Chen SY, Long AM. Chemical speciation of 12 metals in surface sediments from the northern South China Sea under natural grain size. Mar Pollut Bull 2008;56: 786-92.

Gao XL, Chen CTA, Wang G, Xue QZ, Tang C, Chen SY. Environmental status of Daya Bay surface sediments inferred from a sequential extraction technique. Estuar Coast Shelf Sci 2010;86:369-78.

Gao XL, Yang YW, Wang CY. Geochemistry of organic carbon and nitrogen in surface sediments of coastal Bohai Bay inferred from their ratios and stable isotopic signatures. Mar Pollut Bull 2012;64:1148-55.

Gao XL, Li PM, Chen CTA. Assessment of sediment quality in two important areas of mariculture in the Bohai Sea and the northern Yellow Sea based on acid-volatile sulfide and simultaneously extracted metal results. Mar Pollut Bull 2013;72:281-8.
Guo WH, Liu XB, Liu ZG, Li GF. Pollution and potential ecological risk evaluation of heavy metals in the sediments around Dongjiang Harbor, Tianjin. Procedia Environ Sci 2010;2:729-36

Hakanson L. An ecological risk index for aquatic pollution control. A sedimentological approach. Water Res 1980;14:975-1001.

He GK. Levels of heavy metals in molluscs from the coastal region of Bohai Sea and Huanghai Sea. China Environ Sci 1996;16(2):96-100. [In Chinese with English abstract].

He ZP, Song JM, Zhang NX, Xu YY, Zheng GX, Zhang P. Variation characteristics and controlling factors of heavy metals in the South Yellow Sea surface seawaters. Environ Sci 2008;29(5):1153-62. [In Chinese with English abstract].

Hu NJ, Shi XF, Liu JH, Huang P, Yang G, Liu YG. Distributions and impacts of heavy metals in the surface sediments of the Laizhou Bay. Adv Mar Sci 2011;29:63-71. [In Chinese with English abstract].

Hu BQ Li GG, Li J, Bi JQ Zhao JT, Bu RY. Spatial distribution and ecotoxicological risk assessment of heavy metals in surface sediments of the southern Bohai Bay, China. Environ Sci Pollut Res 2013a;185:5071-83.

Hu BQ Li J, Zhao JT, Yang J, Bai FL, Dou YG. Heavy metal in surface sediments of the Liaodong Bay, Bohai Sea: distribution, contamination, and sources. Environ Monit Assess 2013b;20:4099-110.

Huang XQ Liang K, Liu X. The distribution and assessment of heavy metals in surficial sediments in the Pearl River Estuary. Trans Oceanol Limnol 2006;3:27-36. [In Chinese with English abstract].

Jiang GB, Shi JB, Feng XB. Mercury pollution in China. Environ Sci Technol 2006;40: 3672-8.

Kang YD. Distribution and seasonal variation of phytoplankton in the Bohai Sea. Mar Fish Res 1991;12:31-54. [In Chinese with English abstract].

Li SY, Hao J. The study of environmental background concentrations of $\mathrm{Cu}, \mathrm{Pb}, \mathrm{Zn}$ and $\mathrm{Cd}$ in the sediment of the Bohai Bay and its adjacent sea area. Oceanol Limnol Sin 1992;23:39-48. [In Chinese with English abstract].

Li RW, Li Y. Environmental and sedimentological survey along the coast of Bohai Gulf. Acta Sedimentol Sin 2008;26:128-38. [In Chinese with English abstract].

Li SY, Liu GX. The distribution and environmental background values of the heavy metals in sediment of the Bohai Sea. China Environ Sci 1994;14:370-6. [In Chinese with English abstract].

Li B, Zhu M. The pigment species and distribution characteristics of phytoplankton in autumn in Bohai Sea. J Oceanogr Huanghai Bohai Seas 1992;10:32-7. [In Chinese with English abstract]

Li SY, Liu GX, Miao FM. The distribution and environmental background values of the heavy metals in sediment of the Bohai Sea. China Environ Sci 1994;14(5):370-6. [In Chinese with English abstract].

Li SY, Miao FM, Liu GX, Du RZ. The study of pollution history of heavy metals in Bohai Sea. Mar Environ Sci 1996;15(4):28-31. [In Chinese with English abstract].

Li XY, Liu LJ, Wang YG, Luo GP, Chen X, Yang XL, et al. Integrated assessment of heavy metal contamination in sediments from a coastal industrial basin, NE China. PLoS One 2012;7:e39690

Liang LN, Shi JB, He B, Jiang GB, Yuan CG. Investigation of methylmercury and total mercury contamination in mollusk samples collected from coastal sites along the Chinese Bohai Sea. J Agric Food Chem 2003;51:7373-8.

Liang LN, He B, Jiang GB, Chen DY, Yao ZW. Evaluation of mollusks as biomonitors to investigate heavy metal contaminations along the Chinese Bohai Sea. Sci Total Environ 2004;324:105-13.

Ling M. Study on the mercury species and release of mercury from sea water to the atmosphere in Jiaozhou Bay in winter. Master thesis of Ocean University of China; 2010.

Liu MX, Li GJ, Gu HK. Trace metal concentration in fish, Crustacea and Mollusca of the Bohai Bay. Acta Sci Circumst 1983;3(2):149-55. [In Chinese with English abstract].

Liu C, Wang ZY, He Y. Water pollution in the river mouths around Bohai Bay. Int J Sediment Res 2003;18(4):326-32.

Liu F, Wang HT, Wang DL. Spatial distributions of heavy metals from the Laizhou Bay littoral wetland. Adv Mar Sci 2004;22:486-92. [In Chinese with English abstract].

Liu WX, Chen JL, Lin XM, Fan YS, Tao S. Residual concentrations of micropollutants in benthic mussels in the coastal areas of Bohai Sea, North China. Environ Pollut 2007; 146:470-7.

Liu BL, Hu K, Jiang ZL, Qu FG, Su X. A 50-year sedimentary record of heavy metals and their chemical speciations in the Shuangtaizi River estuary (China): implications for pollution and biodegradation. Front Environ Sci Eng China 2011a;5:435-44.

Liu SG, Lou S, Kuang CP, Huang WR, Chen WJ, Zhang J, et al. Water quality assessment by pollution-index method in the coastal waters of Hebei Province in western Bohai Sea, China. Mar Pollut Bull 2011b;62:2220-9.

Liu WX, Qiu WX, Chen JL. Distribution characteristics of trace pollutants in benthic mussels from the coastal areas of Bohai Sea and North Yellow Sea. Environ Sci 2011c;32:445-51. [In Chinese with English abstract].

Liu XL, Zhang LB, You LP, Cong M, Zhao JM, Wu HF, et al. Toxicological responses to acute mercury exposure for three species of Manila clam Ruditapes philippinarum by NMR-based metabolomics. Environ Toxicol Pharmacol 2011d;31:323-32.

Liu XL, Zhang LB, You LP, Yu JB, Cong M, Wang Q, et al. Assessment of clam Ruditapes philippinarum as heavy metal bioindicators using NMR-Based metabolomics. Clean Soil, Air, Water 2011e;39:759-66.

Long ER, MacDonald DD, Smith SC, Calder FD. Incidence of adverse biological effects within ranges of chemical concentrations in marine and estuarine sediments. Environ Manage 1995;19:81-97.

Long ER, Jay Field L, MacDonald DD. Predicting toxicity in marine sediments with numerical sediment quality guidelines. Environ Toxicol Chem 1998;17:714-27.

Luo W, Lu YL, Wang TY, Hu WY, Jiao WT, Naile JE, et al. Ecological risk assessment of arsenic and metals in sediments of coastal areas of northern Bohai and Yellow Seas, China. Ambio 2010:39:367-75. 
Luo W, Wang T, Jiao WT, Hu WY, Naile JE, Khim JS, et al. Mercury in coastal watersheds along the Chinese Northern Bohai and Yellow Seas. J Hazard Mater 2012;215:199-207.

Luo W, Lu YL, Wang TY, Kong PR, Jiao WT, Hu WY, et al. Environmental concentrations and bioaccumulations of cadmium and zinc in coastal watersheds along the Chinese Northern Bohai and Yellow Seas. Environ Toxicol Chem 2013;32(4):831-40.

Ma JR, Shao MH, Bao YE, Yin JS. Current status and assessment of bays of Bohai Sea and Huanghai Sea in Liaoning Province. Res Environ Sci 1995;8:27-34. [In Chinese with English abstract].

MacDonald DD, Scott Carr R, Calder FD, Long ER, Ingersoll CG. Development and evaluation of sediment quality guidelines for Florida coastal waters. Ecotoxicology 1996;5:253-78.

Mao TY, Dai MX, Peng ST, Li GL. Temporal-spatial variation trend analysis of heavy metals (Cu, Zn, Pb, Cd, Hg) in Bohai Bay in 10 years. J Tianjin Univ 2009;42:817-25. [In Chinese with English abstract].

Meng W, Qin YW, Zheng BH, Zhang L. Heavy metal pollution in Tianjin Bohai Bay, China. J Environ Sci 2008;20:814-9.

MHPR (Ministry of Health of the People's Republic of China). Hygienic standard for fresh and frozen marine products of animal origin (GB2733-2005); 2005 [in Chinese]

Müller G. Index of geoaccumulation in sediments of the Rhine River. GeoJournal 1969;2: 108-18.

National Bureau of Statistics of China. China Statistical Yearbook 2011. Beijing: China Statistics Press; 2011 [1057 pp.]. [In Chinese]

Pan K, Wang WX. Trace metal contamination in estuarine and coastal environments in China. Sci Total Environ 2012;42:3-16

Pan JM, Sun WP, Yu PS. Major heavy metal elements in water of the Bohai Sea. In: Hong HS, editor. Regional oceanography of China Seas - chemical oceanography. Beijing, China: Ocean Press; 2012. p. 57-66. [In Chinese].

Pardo R, Barrado E, Lourdes P, Vega M. Determination and speciation of heavy metals in sediments of the Pisuerga river. Water Res 1990;24:373-9.

Pauly D, Christensen V, Dalsgaard J, Froese R, Torres JF. Fishing down marine food webs. Science 1998;279:860-3.

Peng ST, Wu C, Dai MX, Zhan SF, Zhou R, Bai ZP. Distribution of dissolved heavy metals in sea water of the Bohai Bay. In: Yin J, Wei X, Dai X, editors. 6th International Symposium of Asia Institute of Urban Environment: Energy Conservation and Carbon Off in Asia City. Changchun, China: Jilin Publishing Group Ltd; 2009. p. 693-6. [SEP 20, Changchun, China].

Qin YW, Meng W, Zhang BH. Contaminative features of heavy metals for tidal sediment cores in Tianjin Bohai Bay. Environ Sci 2006a;27:268-73. [In Chinese with English abstract].

Qin YW, Meng W, Zheng BH, Su YB. Heavy metal pollution in tidal zones of Bohai Bay using the dated sediment cores. J Environ Sci 2006b;18:610-5.

SEPA (State Environmental Protection Administration of China). Beijing: Standards Press of China; 1997. [In Chinese].

SEPA (State Environmental Protection Administration of China). Marine biological quality (GB 18421-2001). Beijing: Standards Press of China; 2001. [In Chinese]

SEPA (State Environmental Protection Administration of China). Marine sediment quality (GB 18668-2002). Beijing: Standards Press of China; 2002. [In Chinese].

SOA (State Oceanic Administration of China). Marine Environmental Quality Bulletin of China. http://www.coi.gov.cn/gongbao/huanjing/201304/t20130401_26428. html, 2012. [In Chinese].

Sun WP, Pan JM, Lu HY, Xue B. Distribution of dissolved trace metals in summer and winter of 2006 in Changjiang River Estuary and Hangzhouwan Bay. J Mar Sci 2009;31:79-84. [In Chinese].

Tang QS, Meng TX. Atlas of the ecological environment and living resources in the Bohai Sea. Qingdao: Qingdao Press; 1997 [242 pp., In Chinese with English abstract].

Tang AK, Liu RH, Ling M, Xu LQ Wang JY. Distribution characteristics and controlling factors of soluble heavy metals in the Yellow River Estuary and adjacent Sea. Procedia Environ Sci 2010;2:1193-8.

Tessier A, Campbell PGC, Bisson M. Sequential extraction procedure for the speciation of particulate trace metals. Anal Chem 1979;51:844-51.

Tian L, Chen HT, Du JT, Wang XH. Factors influencing distribution of soluble heavy metals in north Yellow Sea surface seawaters. Period Ocean Univ China 2009;39:617-21. [In Chinese with English abstract].

Wan L, Wang NB, Li QB, Zhou ZC, Sun B, Xue K, et al. Estival distribution of dissolved metal concentrations in Liaodong Bay. Bull Environ Contam Toxicol 2008a;80:311-4.

Wan L, Wang NB, Li QB, Sun B, Zhou ZC, Xue K, et al. Distribution of dissolved metals in seawater of Jinzhou Bay, China. Environ Toxicol Chem 2008b;27:43-8.

Wang SC. Grand prospect of this century: the canal connecting Jiaozhou Bay and Laizhou Bay. Jinan: Shandong Education Press; 2007 [390 pp., In Chinese].

Wang CY, Wang XL. Spatial distribution of dissolved Pb, Hg, Cd, Cu and As in the Bohai Sea. J Environ Sci 2007;19:1061-6.

Wang YW, Liang LN, Shi JB, Jiang GB. Study on the contamination of heavy metals and their correlations in mollusks collected from coastal sites along the Chinese Bohai Sea. Environ Int 2005a;31:1103-13.

Wang YW, Liang LN, Shi JB, Jiang GB. Chemometrics methods for the investigation of methylmercury and total mercury contamination in mollusks samples collected from coastal sites along the Chinese Bohai Sea. Environ Pollut 2005b;135:457-67.

Wang H, Xu Q Yang HS. Heavy metal contents and quality evaluation of scallop in northern China seas. Mar Sci 2007;31:11-8. [In Chinese with English abstract].
Wang J, Chen S, Xia T. Environmental risk assessment of heavy metals in Bohai Sea, North China. Procedia Environ Sci 2010a;2:1632-42.

Wang SF, Jia YF, Wang SY, Wang X, Wang H, Zhao ZX, et al. Fractionation of heavy metals in shallow marine sediments from Jinzhou Bay, China. J Environ Sci 2010b;22:23-31.

Wang J, Liu RH, Yu P, Tang AK, Xu LQ, Wang JY. Study on the pollution characteristics of heavy metals in seawater of Jinzhou Bay. Procedia Environ Sci 2012;13:1507-16.

Wang Y, Liu RH, Fan DJ, Yu P, Wang JY, Tang AK. Distribution and accumulation characteristics of heavy metals in sediments in southern sea area of Huludao City, China. Chin Geogr Sci 2013;23(2):194-202.

Wei H, Sun J, Moll A, Zhao L. Phytoplankton dynamics in the Bohai Sea - observations and modelling. J Mar Syst 2004;44:233-51.

WHO. Toxicological evaluation of certain food additives and contaminants. Joint FAO/WHO expert committee on food additives. WHO food additives seriesGeneva: World Health Organization; 1982. p. 28-35.

Wu XY, Liu RH, Qin J, Sun PY, Gao ZW, Jia YG. Study on the variance character of heavy metals contents in sediments in Yellow River Estuary. Trans Oceanol Limnol 2007: 69-74. [In Chinese with English abstract].

Xu SS. Decline mechanisms of fishery resources in the Bohai Sea under anthropogenic activities. [Ph.D. Thesis]Beijing: Graduate University of Chinese Academy of Sciences; 2011 [132 pp., In Chinese with English abstract].

Xu B, Gu ZY, Han JT, Zhang YH, Chen YF, Lu YW. Sequential extractions and isotope analysis for discriminating the chemical forms and origins of $\mathrm{Pb}$ in sediment from Liaodong Bay, China. Arch Environ Contam Toxicol 2009a;57:230-8.

Xu B, Yang XB, Gu ZY, Zhang YH, Chen YF, Lv YW. The trend and extent of heavy metal accumulation over last one hundred years in the Liaodong Bay, China. Chemosphere 2009b;75:442-6.

Xu YY, Song JM, Li XG, Yuan HM, Li N. Variation characteristics and potential ecological risk assessment of heavy metals in the surface sediments of Bohai Bay. Environ Sci 2012;33(3):732-40. [In Chinese with English abstract].

Yang F, Zhao LQ Yan XW, Wang Y. Bioaccumulation of trace elements in Ruditapes philippinarum from China: public health risk assessment implications. Int J Environ Res Public Health 2013;10(4):1392-405.

Yellow Sea Fisheries Research Institute. Mar Fish Res 1991;12:1-122. [In Chinese with English abstract].

Yu T. Study about dissolved heavy metals and their background values in South China Sea. Taiwan Strait 2003;22:329-33. [In Chinese with English abstract].

Yu JL, Li RX. The study on the phytoplankton ecology in the Bohai and Yellow Seas J Oceanogr Huanghai Bohai Seas 1993;11:52-9. [In Chinese with English abstract].

Yue LJ, Shi BC. Monitoring the contaminated situation of the aquatic animals caused by heavy metal in the inshore maritime area of Hulu Island. Environ Monit China 2001;17:45-8. [In Chinese with English abstract].

Zhan SF, Peng ST, Liu CG, Chang Q, Xu J. Spatial and temporal variations of heavy metals in surface sediments in Bohai Bay, North China. Bull Environ Contam Toxicol 2010;84: 482-7.

Zhang W, Wang WX. Large-scale spatial and interspecies differences in trace elements and stable isotopes in marine wild fish from Chinese waters. J Hazard Mater 2012;215-216:65-74.

Zhang B, Tang Q Jin X. Decadal-scale variations of trophic levels at high trophic levels in the Yellow Sea and the Bohai Sea ecosystem. J Mar Syst 2007;67:304-11.

Zhang YF, Wang LJ, Huo CL, Guan DM. Assessment on heavy metals pollution in surface sediments in Jinzhou Bay. Mar Environ Sci 2008;27:178-81. [In Chinese with English abstract].

Zhang WG, Feng H, Chang JN, Qu JG, Xie HX, Yu LZ. Heavy metal contamination in surface sediments of Yangtze River intertidal zone: an assessment from different indexes. Environ Pollut 2009;157:1533-43.

Zhang XL, Ding DW, Xu JS, Liu DW, Wang HY, Tao CF. Heavy metal in seawater and sediment investigation at Bohai Sea western estuary tidal zone. J East China Inst Technol 2010a;33:276-80. [In Chinese with English abstract].

Zhang Y, Song JM, Yuan HM, Xu YY, He ZP, Duan LQ. Biomarker responses in the bivalve (Chlamys farreri) to exposure of the environmentally relevant concentrations of lead, mercury, copper. Environ Toxicol Pharmacol 2010b;30:19-25.

Zhang Y, Song JM, Yuan HM, Xu YY, He ZP. Concentrations of cadmium and zinc in Seawater of Bohai Bay and their effects on biomarker responses in the bivalve Chlamys farreri. Arch Environ Contam Toxicol 2010c;59:120-8.

Zhang QJ, Wang L, Zhao LJ, Sun HW, Lu Y. Analysis and assessment of heavy metal pollution in sediments of Tianjin Harbor and Dagu Drainage canal in Bohai Bay, China. Fresenius Environ Bull 2012;21(7):1777-85.

Zheng N, Wang QC, Liang ZZ, Zheng DM. Characterization of heavy metal concentrations in the sediments of three freshwater rivers in Huludao City, Northeast China. Environ Pollut 2008; 154:135-42.

Zhou XY, Wang ED, Zhu EJ. Evaluation on heavy metal pollution in the sediments at the river mouths around Liaodong Bay. Environ Chem 2004;23:321-5. [In Chinese with English abstract].

Zhuang W, Gao XL. Acid-volatile sulfide and simultaneously extracted metals in surface sediments of the southwestern coastal Laizhou Bay, Bohai Sea: concentrations, spatial distributions and the indication of heavy metal pollution status. Mar Pollut Bull 2013. http://dx.doi.org/10.1016/j.marpolbul. 2013.09.016. 